\title{
Mesorhizobium Ciceri as a Biological Tool for Improving Physiological, Biochemical and Antioxidant State of Cicer Aritienum L. by Lowering the Fungicide Induced Oxidative Stress
}

Mohammad Shahid ( $\nabla$ shahidfaiz5@gmail.com )

Aligarh Muslim University

Mohammad Khan

Aligarh Muslim University

\section{Research Article}

Keywords: C. arietinum, Kitazin, Phytotoxicity and Oxidative damage, Mesorhizobium ciceri, Active Biomolecules, Growth promotion, Yield

Posted Date: December 9th, 2020

DOl: https://doi.org/10.21203/rs.3.rs-117358/v1

License: (c) (1) This work is licensed under a Creative Commons Attribution 4.0 International License. Read Full License

Version of Record: A version of this preprint was published at Scientific Reports on May 6th, 2021. See the published version at https://doi.org/10.1038/s41598-021-89103-9. 


\section{Abstract}

The present study demonstrates the interactions of fungicide-tolerant symbiotic bacteria Mesorhizobium ciceri with Cicer arietinum-kitazin (KITZ) in greenhouse conditions. Under both in vitro and soil systems, KITZ imparted deleterious impacts on plants as a function of dose. The three-time KITZ dose detrimentally and maximally reduced germination efficiency, vigor index, dry matter production, symbiosis, leaf pigments and seed attributes of $C$. arietinum. KITZ- induced morphological alterations in root tips, oxidative damage and cell death in root cells of $C$. arietinum were shown by SEM. M. ciceri tolerated up to $2400 \mathrm{\mu gmL}^{-1}$ of $\mathrm{KITZ}$, synthesized considerable amounts of bioactive molecules including indole-3-acetic-acid (IAA), 1-aminocyclopropane 1-carboxylate (ACC) deaminase, siderophores, exopolysaccharides (EPS), HCN and ammonia, and solubilised inorganic phosphate even in fungicidestressed media. Following application to soil, $M$. ciceri improved performance of $C$. arietinum and enhanced dry biomass production, yield, symbiosis and leaf pigments even in a fungicide-polluted

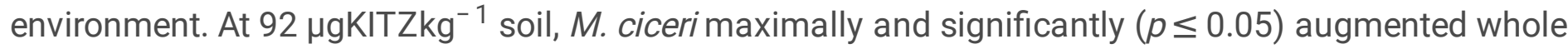
plant length by $41 \%$, total dry biomass by $18 \%$, carotenoid content by $9 \%$, LHb content by $21 \%$, root $\mathrm{N}$ by $9 \%$, shoot $\mathrm{P}$ by $11 \%$ and pod yield by $15 \%$. Additionally, M. ciceri was associated with decreased levels of stressor molecules (proline and MDA) and antioxidant defence enzymes (APX, GPX, CAT and POD) of $C$. arietinum plants when inoculated in soil. The symbiotic strain effectively colonized the plant rhizosphere/rhizoplane. In pesticide- contaminated soils, inoculation of $M$. ciceri may serve as an excellent strategy for augmenting $C$. arietinum productivity.

\section{Introduction}

Cicer arietinum L. (chickpea) crops often suffer from attack by phytopathogens, which damage the crop and consequently limits crop yield. Fungicides are commonly used to enhance productivity by preventing phytopathogen-related damage (Shahid et al., 2020). However, massive and injudicious use of such chemicals can upset soil fertility and inhibit microbial communities (Walia et al., 2014) and enzymatic activities (Han et al., 2020). Apart from the cytotoxic and genotoxic effect of fungicides on soil microbiota, uptake and translocation of pesticides by different plant organs may severely damage important metabolic activities leading subsequently to death of plants (Eker et al., 2006). Exceptionally high concentrations of pesticides disrupt: (i) cellular organelles and membrane permeability (Shahzad et al., 2018); (ii) respiratory processes and carbohydrate metabolism (Kumar et al., 2012); (iii) physiologically active enzymes (Liu et al., 2006) and proteins (Yin et al., 2016); (iv) photosystems by blocking the effective quantum yield of PSII (ФPSII) and quantum efficiency of PSII (Fv/Fm) (Niinemets and Kull, 2001); and (v) cause oxidative damage (Singh and Roy, 2017) and genetic makeup of cellular machinery (Gill and Tuteja, 2010). Zablotowicz and Reddy (2007) observed that the pesticide glyphosate considerably decreased nitrogenase activity of rhizobia. As a consequence, symbiotic events leading to nodule formation and root morphogenesis of plants were drastically diminished (Adami et al., 2017). In another study, the fungicide pyrimorph was found to strongly inhibit the electron transport (ET) reactions of chloroplasts and adversely affected the physiology of whole plants (Xiao et al., 2014). 
To overcome these problems, certain physico-chemical approaches have been used to destroy pesticides in soil. However, these methods are expensive, and the remediation process often remains incomplete due to the transformation of the parent compound to metabolites which are sometimes more persistent and more toxic for non-target organisms than were the parent compounds. As a consequence, physicochemical methods of pesticide removal have not been widely accepted. Alternative methods of pesticide degradation/detoxification are therefore necessary. Bioremediation offers some solutions to pesticide detoxification problems. This technique, often referred to as 'microbial remediation' relies on the identification of microorganisms to convert contaminants to simpler and harmless forms and hence, to mitigate pesticide pollution.

To this end, scientists have identified pesticide degrading/detoxifying microbes endowed with potential plant growth promoting activities. Chief among them belongs to genera Ensifer (Ma et al., 2017), Bradyrhizobium (Romdhane et al., 2016), Rhizobium (Hang et al., 2019), Alcaligenes (Silambarasan and Abraham, 2013), Actinobacteria (Lang et al., 2018) and Bacillus (Tang et al., 2018). Apart from degradation of toxic pollutants, plant growth promoting rhizobacteria (PGPR) have the ability to synthesize growth regulating substances. By expressing multifarious physiological activities, PGPR promotes the overall growth and yield of legumes (Matse et al., 2020) raised in soil contaminated during cultivation with pesticides. For instance, inoculation of Azotobacter (Gothandapani et al., 2017) and Bacillus (Lastochikna et al., 2017) had positive effects on pulses where they supplied $N$ and growth stimulating substances including phytohormones, siderophores and EPS, and solubilized soil P. Some fungicide-tolerant and $\mathrm{N}_{2}$-fixing bacterial strains such as Rhizobium and Azotobacter and Gram-positive Bacillus sp. detoxified pesticides and enhanced legume production under adverse conditions (Alori et al., 2017). Likewise, pesticide-tolerant free-living PGPR such as Bacillus (Roy et al., 2018), Azotobacter (Gurikar et al., 2016) and Stenotrophomonas (Jaiswal et al., 2019) circumvented the toxicity of pesticides and concurrently improved growth of legumes.

Given the nutritive importance of $C$. arietinum in the diet, the negative impact of fungicides on crop productivity, the lack of adequate information on fungicidal response to $C$. arietinum and the bioremediation potential of PGPR, this study was formulated. The objectives were to: (i) assess the fungicidal toxicity to $C$. arietinum both under in vitro bioassays and pot-house conditions; (ii) assess the kitazin-induced distortion, oxidative damage and cell death in $C$. arietinum root cells; (iii) isolate and identify the symbiotic bacterium from $C$. arietinum root nodules; (iv) evaluate fungicidal tolerance by nodule bacteria; ( $v$ ) determine the production of bioactive molecules under fungicide stress; (vi) evaluate the effects of $M$. ciceri on physiological and biochemical attributes of $C$. arietinum; (vii) determine the stressor molecules and antioxidant enzymes from $C$. arietinum foliage detached from fungicide-treated and bio-inoculated plants; and (viii) evaluate the rhizosphere/rhizoplane colonization potential of $M$. ciceri.

\section{Materials And Methods}




\subsection{Toxicity Assessment of Kitazin to Cicer arietinum Under In-Vitro Conditions}

\subsubsection{Seed Germination, Vigor Index and Plant Length}

Healthy and vigorous seeds of $C$. arietinum were soaked in water to imbibe for $24 \mathrm{~h}$. Seeds were disinfected with $3 \% \mathrm{NaOCl}$ solution and carefully rinsed with sterile water. Soft agar (0.7\%) plates supplemented with different concentrations of KITZ (for detail, see supplementary table S1) were poured. Soft agar plates without fungicide treatment were served as a control for the sake of comparison. Seeds were placed on the soft agar plates and kept at room temperature $\left(28 \pm 2{ }^{0} \mathrm{C}\right)$ for $3-4$ days. After $6-7$ days of incubation, germination percentage, vigor index, radicle and plumule lengths of the plantlets were recorded.

\subsubsection{Percent phytotoxicity, Tolerance Index (TI) and Root- Shoot Length Ratio}

Additionally, the phytotoxicity (\%), tolerance index and ratio of root and shoot length was recorded in fungicide treated/untreated $C$. arietinum seedling. (See the electronic supplementary information for details).

\subsection{Micro-morphological Alteration, Oxidative Damage and Cytotoxicity in C. arietinum Root}

\subsubsection{Alteration in Root Tip Morphology analyzed by SEM}

Morphological analysis of $C$. arietinum roots was done under scanning electron microscopy (JSM 6510 LV, JEOL, Japan) following the treatment of roots on soft agar $(0.7 \% \mathrm{w} / \mathrm{v})$ amended with $1000 \mu \mathrm{g} \mathrm{mL}$ ${ }^{1} \mathrm{KITZ}$. After seven days of germination, roots were picked up from the agar plates and rinsed at least thrice with sterile phosphate buffer saline (PBS) and then fixed and processed following our previously described protocol for tissue fixation for SEM (Ahmed et al., 2018). Fixed and ethanol dehydrated tissues were examined under SEM at $10 \mathrm{kV}$ accelerating voltage to check the fungicide induced distortion/damage in root tips, if any. A control set was also included for comparison.

\subsubsection{Oxidative Damage and Cell Death by CLSM analysis}

Confocal laser scanning microscopy of KITZ treated root was performed to check the cytotoxic potential and membrane damage. For the assay, seedlings were grown on soft agar as described for SEM analysis. Roots from seven days grown seedlings were carefully detached from soft agar and washed with buffer. Roots were tagged with a mixture of two fluorescent tags (i) acridine orange (10 $\mu \mathrm{g} \mathrm{mL})$ and (ii) propidium iodide $(25 \mu \mathrm{M})$ and visualized for any membrane compromised dead cells under LSM-780 Confocal Microscope (Zeiss, Germany). In order to differentiate between metabolically active and inactive cells, loss of plant cell membrane was used as a toxicity indicator. A well-adapted Evans blue staining 
procedure was followed (Ref). C. arietinum roots grown in the presence of three concentrations ( $1 \mathrm{X}, 2 \mathrm{X}$, and $3 X$ ) of KITZ were allowed to take up the $0.25 \%$ w/v solution of Evans blue stain for at least 15 min. After gentle washing with DDW thrice, emission of fluorescence was examined under LSM-780.

\subsection{Isolation of Root Nodule Bacteria and Kitazin Tolerance}

Fresh and un-damaged healthy nodules were detached from Cicer arietinum (chickpea) plants and surface sterilized by dipping nodules in $4 \% \mathrm{NaOCl}$ for $2 \mathrm{~min}$., washed three times with sterile double distilled water (DDW) and crushed gently. A-100 $\mu \mathrm{L}$ freshly extracted nodule suspensions were streaked on YEMA plates and incubated at $28 \pm 2{ }^{\circ} \mathrm{C}$ for $3-5$ days. A total of 20 Mesorhizobium strains were isolated and morphologically and biochemically identified (Holt et al., 1994). Plant infection technique was carried out to determine the host specificity (Vincent, 1970). Mesorhizobial isolates were exposed to varying concentrations of kitazin using minimal salt agar (MSA) in order to select pesticide tolerant Mesorhizobium strain. Colonies grown on YEMA plates and efficiently surviving at the highest concentration of pesticides were chosen and referred to as pesticide tolerant mesorhizobial strains (PTMS). Of the total 20 Mesorhizobium isolates, BRM5 expressing maximum tolerance to pesticides was selected.

\subsection{Molecular Identification of BRM5 Isolate}

For the identification of isolate to genus level, 16S rRNA sequencing was performed (Shahid et al. 2020). (See the supplementary method section for detailed methods of DNA isolation, PCR and sequencing).

\subsection{Production of PGP Active Biomolecules under Fungicidal Pressure}

\subsubsection{Indole acetic acid (IAA), Siderophore Production and ACC Deaminase Activity}

The IAA produced by Mesorhizobium ciceri BRM5 was quantitatively assessed by modified method of Brick et al. (1991). For the assay, strain M. ciceri was cultured in LB broth containing a fixed amount $\left(100 \mu \mathrm{g} \mathrm{mL}^{-1}\right.$ ) of tryptophan and amended with 600 (1X), 1200 (2X) and 1800 (3X) $\mathrm{gg} \mathrm{mL}^{-1}$ of KITZ (See supplementary methods for details).

The isolate was spot inoculated on kitazin supplemented universal chrome azurol S (CAS) agar plates followed by incubation at $28 \pm 2{ }^{\circ} \mathrm{C}$ for detection of orange colour halo around the bacterial colonies. Also, the siderophore was quantitatively assessed by growing the bacterial strain in fungicide amended iron (Fe) free succinate liquid medium as suggested by Barbhaiya and Rao (1985). The estimation of siderophore was done according to universal chrome azurol liquid assay (Schwyn and Neilands 1987). Siderophore units were calculated as follows: 


\section{$\%$ Siderophore unit $=\frac{\lambda \text { of reference }(\mathrm{Ar})-\lambda \text { of test }(\mathrm{As})}{\lambda \text { of reference }(\mathrm{Ar})} \times 100$}

For ACC deaminase activity, M. ciceri was cultured in broth supplemented with various kitazin concentrations and amount of a-ketobutyrate produced by strain was determined following the method of Honma and Shimomura (1978) and Penrose and Glick (2003) (See supplementary methods).

\subsubsection{EPS production, HCN and Ammonia Production}

Exopolpysaccharide (EPS) produced by M. ciceri under fungicide stress was scrutinized by culturing the cells into liquid medium supplemented with variable doses of KITZ (see supplementary method for details). The production of cyanogenic compound ( $\mathrm{HCN})$ and ammonia were assayed using the methods of Bakker and Shipper (1987) and Dye (1962), respectively.

\subsection{Crop-Based Experiments}

\subsubsection{Planting, Fungicide Treatment and Application of Mesorhizobium}

Seeds were disinfected/sterilized with $\mathrm{NaOCl}(2 \%)$, washed, cleaned and desiccated at room temperature. Commercial grade fungicide kitazin (Table S1) [recommended dose: $1 \times\left(96 \mu \mathrm{g} \mathrm{Kg}^{-1}\right), 2 \times\left(192 \mu \mathrm{gKg}^{-1}\right)$ and $\left.3 \times\left(288 \mu \mathrm{gKg}^{-1}\right)\right]$ of soil were applied to moist experimental soils before sowing of seeds (at least one day before sowing). The soils were filled in $20 \times 24 \mathrm{~cm}$ clay pots of having approximately $5 \mathrm{~kg}$ soil per pot. Seeds were then coated/bacterized with freshly prepared inoculum of $M$. ciceri after dipping the seeds in liquid culture medium for $2 \mathrm{~h}$ using $10 \%$ gum arabic as a sticker to achieve $1 \times 10^{8}$ cells seed $^{-1}$ which was confirmed by viable cell count. The un-inoculated sterilized seeds submerged in sterile water only were taken as control. Non-bacterized and bio primed seeds $(n=10)$ were sown in respective earthen pots containing $5 \mathrm{~kg}$ of conventional soils. Two controls were run in parallel; one was un-inoculated and untreated control (without bacteria and without fungicides) and another was inoculated (only bacteria but no fungicides). Each test concentration was replicated thrice and pots were arranged in a completely randomized block design. After germination, seedlings were thinned and two uniform healthy seedlings of $C$. arietinum were maintained in each pot, 15 days after emergence (DAE). Pots were watered regularly and were kept in open field condition. The crop experiments were carried out regularly for two succeeding years to achieve the consistency in results.

\subsubsection{Germination Efficiency, Plant height, Dry biomass and Photosynthetic Pigment in the presence of M. ciceri and KITZ}


The KITZ treated and bacterized $C$. arietinum plants were removed at 80 and 120 DAS and germination efficiency, root and shoot length, weight and dry biomass was measured. For dry biomass, plants were dried in oven (Yorco, York Scientific Industries, Pvt. Ltd. India) at $80{ }^{\circ} \mathrm{C}$ for 2 days and then weighed using an electronic scale balance (BL-220 H, Shimadzu, Japan), and average was calculated. Leaf

photosynthetic molecules (chlorophyll and carotenoid) accumulated in fungicide treated/untreated and bacterized $C$. arietinum foliage was estimated following the methods of Arnon (1949) and Kirk and Allen (1965), respectively (See supplementary methods in electronic supporting information).

\subsubsection{Symbiosis, Nutrient Uptake and Seed attributes}

Symbiotic features of $C$. arietinum were assayed by carefully removing the nodules from root systems. Nodules were counted and oven dried $\left(80^{\circ} \mathrm{C}\right)$ in a ventilated oven for $48 \mathrm{~h}$. After drying, nodule dry biomass (mg plant ${ }^{-1}$ ) was weighed using an electronic scale balance (BL-220 H, Shimadzu, Japan) and average was calculated. Furthermore, leghaemoglobin $(\mathrm{LHb})$ content was quantitatively assayed following the earlier demonstrated method of Shahid and Khan (2018). (see electronic supporting information).

The nutritional content (nitrogen and phosphorous) in fungicide treated and bacterized $C$. arietinum plants was estimated at harvest as previously described by Jackson (1976) and Lindner (1944), respectively. Seed yield was recorded. Grain protein was extracted and estimated following the method of Lowry (Lowry et al., 1951). (See supplementary methods).

\subsection{Assessment of Oxidative Stress Parameters in Bio inoculated and treated $\mathrm{C}$. arietinum}

\subsubsection{Estimation of Proline and MDA Content (Lipid Peroxidation)}

The free proline and MDA content in various organs of $C$. arietinum cultivated with/without the amendment of fungicide was assayed as demonstrated earlier (Bates et al., 1973) (See supplementary methods).

\subsection{Extraction and Determination of Antioxidant Enzymes}

For antioxidant enzyme activity, foliage was crushed in $4 \mathrm{~mL}$ of enzyme extraction buffer [( $50 \mathrm{mM}$ phosphate buffer ( $\mathrm{pH}=7.8)$ ] containing $1 \mathrm{mM}$ EDTA and $2 \%(\mathrm{w} / \mathrm{v})$ polyvinylpyrrolidone (PVP). For GPX (E.C. 1.11.1.7), foliage tissues $(100 \mathrm{mg})$ were homogenized in tris-buffer and the homogenate was centrifuged at $12,000 \mathrm{rpm}$ for $20 \mathrm{~min}$. at $4^{\circ} \mathrm{C}$. Increase in absorbance at $470 \mathrm{~nm}$ due to formation of tetra guaiacol $\left(\varepsilon=26.6 \mathrm{mM}^{-1} \mathrm{~cm}^{-1}\right)$ is expressed as $\mu \mathrm{mol} \mathrm{mg} \mathrm{protein}{ }^{-1} \mathrm{~min}^{-1}$. The reaction mixture $(3 \mathrm{~mL})$ consisted of $100 \mathrm{mM}$ phosphate buffer ( $\mathrm{pH}=7.0), 0.1 \mathrm{mM}$ EDTA and $20 \mathrm{mM} \mathrm{H}_{2} \mathrm{O}_{2}$. The reaction was initiated by adding $100 \mu \mathrm{L}$ of enzyme extract. The POD (E.C. 1.11.1.7) and APX (E.C. 1.11.1.11) activities 
were determined following the modified methods of Leonards et al. (2004) and Hammerschmidt et al. (1982), respectively. All enzyme assays were performed three times with three replicates of each assay.

\subsection{Rhizosphere and Rhizoplane Colonization by M. ciceri under Stress}

The colonization of root surface by $M$. ciceri was determined in the presence/absence of fungicide. For the examination, roots were rinsed with DDW and PBS. The scanning electron microscopy was performed following the method of Shahid et al. (2019). Furthermore, the colonization of roots in term of CFU g ${ }^{-1}$ of root material was determined at 40 and 80 DAS after exposure with different concentrations of fungicides.

\subsection{Statistical analyses}

The data were statistically analyzed using Sigma Plot 12.0 and Minitab17 software. Complete randomized block design (CBRD) for pot experiments was followed with at least three pots per individual test concentration. Crop experiments were conducted for two consecutive years to confirm the reproducibility of data. The data recorded in each year were pooled and analyzed. The mean of the data within a single column was calculated and compared with control treatments. The data represented either in figures or tables is the mean \pm standard deviation (S.D.) of at least three replicates $(n=3)$. Different alphabets in graphs and tables show a significant difference among the treatments at a confidence level of $p \leq 0.05$. The least significant difference (LSD) among treatment means was calculated by two-way analysis of variance (ANOVA) at $p \leq 0.05$.

\section{Results And Discussion}

\subsection{Toxic Impact of Fungicide on $C$. arietinum under In-Vitro Conditions}

\subsubsection{Germination Percentage, Vigor Index and Plant Length}

The impact of dose of KITZ on germination efficiency and seedling attributes of $C$. arietinum seed developed on fungicide-amended agar plates was variable but negative (Fig. 1) The $3 X$ concentration showed pronounced toxicity and significantly $(p<0.05)$ reduced the germination $\%$, vigor index $(\mathrm{SVI})$, and radicle (RL) and plumule (PL) length by $40 \%, 47 \%, 66 \%$ and $79 \%$ compared to control, respectively (Figs. 1 panel a-c). The reduction in germination efficiency and vigor index may possibly due to the distressed germination metabolism caused by the fungicide. Pesticides detrimentally influenced the germination ability of different legumes as reported by various workers. In this regard, lethal effect of fungicides on seedling germination and biological attributes of $P$. sativum under in vitro conditions has been reported (Shahid et. al., 2018). 


\subsubsection{Phytotoxicity \%, Tolerance index (TI) and Root-Shoot Length Ratio}

A $19 \%, 42 \%$ and $88 \%$ phytotoxicity was recorded for $C$. arietinum when grown with 96,192 and $288 \mu \mathrm{g}$ $\mathrm{KITZ} \mathrm{kg}{ }^{-1}$, respectively, compared to control (Fig. 1e). The higher KITZ concentration (3X) maximally affected the root-shoot length ratio and reduced it by $0.9-0.4$ ( $55 \%$ reduction over control) (Fig. $1 \mathrm{~d})$. The tolerance index $(\mathrm{TI})$ in C. arietinum decreased with increasing KITZ doses and confirmed a negative correlation between fungicide and TI. The TI of C. arietinum was recorded at 70,56 and $26 \%$ at $1 \mathrm{X}, 2 \mathrm{X}$ and $3 X$ dose of KITZ respectively; over the untreated control (Fig. 1 panel f). These results indicate that lower fungicide concentrations resulted in maximum $\mathrm{Tl}$, whereas the $3 \mathrm{X}$ dose exhibited the minimum $\mathrm{TI}$ in C. arietinum. Similarly, root-shoot length ratio and tolerance index of chickpea were negatively influenced by the higher concentrations of two neonicitnoid group of pesticides (Shahid et al., 2020).

\subsection{Micro-morphological Root Tip Distortion, Oxidative Stress and Cell Death}

SEM images reveal the inhibitory effects of fungicide to the radicle regions of root tips and their surfaces, which are in the form of cracks/fractures, breakages, crumbling and spears relative to an indistinct, smooth/even and unbroken shape (Fig. 2 panel II B, B1) as shown in the control root tip and surface (Fig. 2 panel II A, A1). The alterations in root tip morphology further validate the fungicide toxicity which, in turn, might have reduced uptake of water and nutrients from soil causing altered root as well as reduced plant growth (Fig. 2 panel I). Similar damage to the micro-morphological structure of roots tips due to the toxicity of pesticides and other toxic pollutants has reported (Shahid et al., 2020; Zeyad et al., 2019; Kumar and Pandey, 2015; Tripathy et al., 2013).

Fungicide-induced oxidative stress in root membranes was also visualized. AO/PI stained and fungicidetreated C. arietinum roots were observed using confocal laser scanning microscopy (CLSM). A concentration-dependent increase in dead/injured cells observed as red/orange color occurred in roots exposed to $3 \mathrm{X}$ of KITZ (Fig. 2 panel III B1 B2 and B3). Untreated root tissues exhibited maximum intensity of green fluorescence resulting from AO reaction representing little or no damage (Fig. 2 panel III B). This is an indication that pesticide exposure was arbitrated by ROS-mediated damage to membrane lipids which therefore increased fluorescence of DNA-bound propidium iodide in membranes. Cortés-Eslava et al. (2018), using CLSM, reported similar oxidative stress, oxidative damage and apoptosis in two model plants grown in insecticide- stressed conditions. The loss/damage of plasma membrane in fungicidetreated root tissue was obvious when $C$. arietinum roots were stained with Evans blue dye. The uptake of dye by root tissues increased three- to four-fold with increasing KITZ concentrations (Fig. 2 panel IV C1, $\mathrm{C} 2$ and C3). In contrast, dye was not taken up by untreated roots (Fig. 2 panel IV C) and hence, the root margin remained smooth signifying its functional integrity.

\subsection{Biochemical and Molecular Identification of Mesorhizobium and Fungicide Tolerance}


Strain M. ciceri was characterized morphologically and biochemically (Table S2). Based on biochemical and cultural characteristics, the genus of the symbiotic bacterium was confirmed and strain was presumed as Mesorhizobium. Isolate BRM5 showed the maximum base sequence similarity (>96.7\%) to type strain Mesorhizobium jarvisii ATCC $233669^{T}$ (Accession number NR135858.1), (Fig. S1). Based on this relatedness, isolate BRM5 was identified as Mesorhizobium ciceri.

The tolerance of $M$. ciceri to KITZ was assessed while grown in minimal salt (MS) broth added with variable concentrations of fungicide; strain BRM5 survived up to $2400 \mu \mathrm{gmL}^{-1}$ of KITZ (Table S2). Achromobacter spanium and Serratia plymuthica tolerated exceptionally high concentrations of different group of pesticides recovered from pesticide-polluted rhizospheres (Aroua et al., 2019). Various workers have isolated the pesticide-tolerant bacterium recovered from nodules of different legumes raised in pesticide-polluted soil (Shahid and Khan, 2020; Shahid et al., 2019a; Shahid et al., 2019 b; Shahid and Khan, 2017; Ahemad and Khan, 2012).

\subsection{PGP Active Biomolecules Produced by M. ciceri under Fungicide Stress}

\subsubsection{IAA, Siderophores and ACC Deaminase}

Pesticide-tolerant $M$. ciceri revealed inconsistent secretion/production of active biomolecules when cultured in both stressed and controlled (fungicide-free) environments. Under controlled conditions $M$. ciceri synthesized $43.3 \pm 3.2 \mu \mathrm{glAAmL}{ }^{-1}$ which decreased with increasing doses of KITZ. This strain synthesized indole-3-acetic acid even when cultured in LB broth supplemented with higher concentrations of fungicide. For example, secretion of IAA was reduced from $43.3 \pm 3.2$ to $32.2 \pm 3.1 \mu \mathrm{glAAmL}^{-1}(25.6 \%$

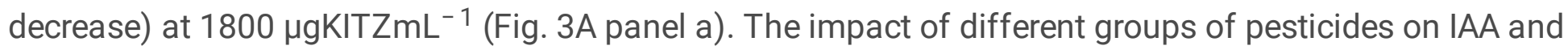
other plant growth regulating active biomolecules of nodule bacterium Bradyrhizobium sp. (Romdhane et al., 2016), B. japonicum (Shahid et al., 2019a) and R. Leguminosarum (Shahid et al., 2019b) have also been reported. Secretion of IAA by the fungicide-tolerant BRM5 strain even at higher levels of pesticide is a promising feature of soil microbes, because such pesticide-tolerant PGPR strains, when used in harsh environments are likely to endure producing/releasing phytohormones such as IAA. This crucial growthaugmenting plant hormone will thus be accessible to plants even at high levels of pesticides. A trend similar to IAA was observed for siderophore production. $M$. ciceri synthesized siderophores even under stressed conditions (Fig. 3A panel b-d). Similar production of siderophores by Rhizobium sp. (Kang et al., 2020; Sijilmassi, et al., 2020), Mesorhizobium sp. (Ahemad and Khan, 2012), Pseudomonas sp. (Khan et al., 2020) and $A$. vinelandii (Shahid et al., 2019) under stressed conditions are reported.

Bacterial ACC deaminase is an outstanding biological attribute which can substantially decrease levels of ethylene $\left(\mathrm{C}_{2} \mathrm{H}_{2}\right)$ in plants and thus, accelerates the functioning of developing plants in harsh environments (Belimov et al., 2015). M. ciceri exhibited a positive response to ACC deaminase even when cultured in fungicide-supplemented medium. Maximum (40.9 $\pm 1.8 \mu \mathrm{M}$ a-Ketobutyrate $\mathrm{mg}^{-1}$ protein hour $\left.{ }^{1}\right)$ and minimum $\left(27.0 \pm 0.87 \mu \mathrm{M}\right.$ a-Ketobutyrate $\mathrm{mg}^{-1}$ protein hour $\left.{ }^{-1}\right)$ amounts of ACC were synthesized 
at 0 and $1800 \mu \mathrm{gITZmL}^{-1}$, respectively (Fig. 3A panel e). Secretion of ACC deaminase by the tolerant strain, however, even in stressed environments is agronomically a beneficial feature for increasing productivity of crops under pesticide stress. This intrinsic property of ACC deaminase production even under pesticide pressure makes them a promising choice for crop production even in soils polluted with excess pesticide.

\subsubsection{EPS and $\mathrm{NH}_{3}$ Production}

EPS synthesized by $M$. ciceri increased with increasing concentrations of fungicide. For example, at 1800 $\mu \mathrm{gKITZmL}{ }^{-1}$ (3X dose), M. ciceri secreted the maximum EPS which was $29 \%\left(165 \pm 12 \mu \mathrm{gmL}^{-1}\right)$ greater than that released under fungicide-free conditions $\left(117 \pm 5.4 \mu \mathrm{gmL}^{-1}\right)$ (Fig. 3A panel f). Furthermore, the EPS secreted by M. ciceri BRM5 (Fig. 3B panel A) showed an enhancement with increasing concentrations of FIP (Fig. 3B panel B). Additionally, the EPS produced by strain was quantified (Fig. 3B panel C) using standard protocols. The structural morphology and topography of dried powder of EPS was done using SEM (Fig. 3B panel D) and AFM (Fig. 3B panel E) techniques. Also, the elemental analysis indicated the presence of some major and trace elements (Fig. 3B panel F). Release of EPS by nodule bacterium both in the absence or presence of stressor molecules (pesticides) could be advantageous for producing bacteria and for growing crops. When EPS are liberated from bacterial cells into their surroundings, EPS may influence the growth of plants even under stressed conditions.

Exopolysaccharides protects bacteria from desiccation, phagocytosis and phage attack (Angelin and Kavitha, 2020) by forming a polymeric network around growing cells, while it protects plants from pathogen attack (Rodríguez-Navarro et al., 2014). In addition, the rhizobia invasion process, formation of the infection thread, bacteroid, and nodules during Rhizobium-legume interactions is greatly influenced by EPS (Gage, 2004). By synthesizing substantial quantities of EPS, bacterial strains can be safeguarded from the noxious effects of contaminants by masking their effects (Ghosh et al., 2019). Due to these benefits, interest in identifying EPS-producing nodule bacteria has increased in recent years (El-Ghany et al., 2020). Similarly, EPS production of PGPR strains under pesticide stress was reported by other workers (Mukherjee et al., 2019; Fatima et al., 2019). Bacterial strain showed the activity of ammonia production at all the concentrations of KITZ (Table 1).

Table 1

Ammonia, $\mathrm{HCN}$ and siderophore production by M. ciceri BRM5 under kitazin stressed condition

\begin{tabular}{|lllll|}
\hline Treatment & $\begin{array}{l}\text { Dose rate }\left(\mathrm{ggmL}^{-}\right. \\
\text {1) }\end{array}$ & $\begin{array}{l}\mathrm{a}^{\mathrm{NH}} \mathrm{g}_{3} \\
\text { Production }\end{array}$ & $\begin{array}{l}\text { b } \mathrm{HCN} \\
\text { Production }\end{array}$ & $\begin{array}{l}\text { Siderophore production }\left(\mathrm{FeCl}_{3}\right. \\
\text { Test })\end{array}$ \\
\hline Control & 0 & ++ & $\mathrm{ND}$ & ++ \\
\hline Kitazin & $600^{*}$ & + & $\mathrm{ND}$ & + \\
& $1200^{\star *}$ & + & $\mathrm{ND}$ & + \\
& $1800^{\star * *}$ & + & $\mathrm{ND}$ & + \\
\hline
\end{tabular}


In this table, *, ** and *** represents the $1 \mathrm{X}, 2 \mathrm{X}$ and $3 \mathrm{X}$ concentrations of kitazin, respectively. ${ }^{\mathrm{a} a m m o n i a,}$ b HCN production. ++ and ND indicate 'positive reaction' and 'not detected', respectively.

\subsection{C. arietinum-Fungicide-Mesorhizobium Interactions: Comprehensive Toxicity and Bioremediation Studies}

Bioinoculation impact of M. cicero on Biochemical Characteristics of C. arietinum

\subsubsection{Seed Germination}

The kitazin tolerant $M$. ciceri improved the growth of plants when applied to $C$. arietinum plants in soil system treated with variable level of fungicide (Fig. 4 panel a). The impact of $M$. ciceri BRM5 on germination efficiency of $C$. arietinum seedlings grown in earthen pots supplemented separately with varying doses of KITZ was variable (Fig. 4 panel b). Generally, strain BRM5 had a positive impact on germination and vigor index relative to un-inoculated seeds. $M$. ciceri BRM5 exhibited a maximum increase of $5 \%$ and $6 \%$ in germination and SVI at $96 \mu$ KITZkg ${ }^{-1}$ (Fig. 4 panel b) compared to the uninoculated but similar dose of fungicide. Microbacterium hydrocarbonoxydans BHUJP-P1, Stenotrophomonas rhizophila BHUJP-P2, B. licheniformis BHUJP-P3 and B. cereus BHUJP-P4 increased germination efficiency and growth of crops even in the presence of varying concentrations of monocrotophos and chlorpyrifos (Jaiswal et al., 2019).

\subsubsection{Length and Weight of Plant Organs}

A gradual increase in length of roots and shoots of $M$. ciceri BRM5-bacterized plants was observed (Fig. 4 panel c) both at 80 and 120 DAS in the presence of variable doses of KITZ. M. ciceriBRM5, when grown with KITZ, imparted maximum benefits on plant organs which decreased considerably at $3 \mathrm{X}$

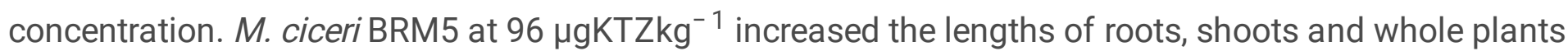
maximally by 11, 7 and $41 \%$ (at 80 DAS) respectively, over sole application of 1X of KITZ (Table S3, Fig. 4 panel c). Similarly, M. ciceri BRM5 increased the fresh weight of roots, shoots and whole plant by 29,18

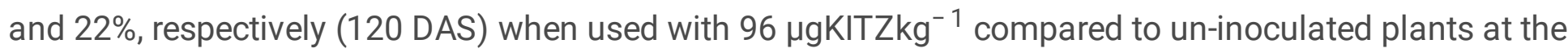
identical dose of KITZ (Table S3, Fig. 4 panel d). Enhancement in plant growth may be due to increased availability of IAA, soluble P, siderophores, and ACC deaminase secreted by the microbial symbiont. Of these, growth regulators like IAA promote root growth directly by stimulating cell elongation or cell division (Pacheco-Villalobos et al., 2016). The well-developed and expanded roots absorb more water and minerals from soil (Rijavec and Lapanje, 2016) which in turn enhance the growth of the plant. Kumar et al. (2017) reported that pesticide-tolerant PGPR strains P. putida and B. amyloliquefaciens alleviated the adverse effect of pesticides and increased soil enzyme activities and seed germination efficiency, elongated plant organs and enhanced other parameters of $C$. arietinum. These findings corroborate our facts that inoculated PGPR degrade/detoxify pesticides and thus, improve various parameters of legumes grown in the affected soil.

\subsubsection{Dry Biomass Accumulation}


The bacterized and un-inoculated $C$. arietinum plants cultivated in soil treated with varying levels of fungicide had variable dry biomass of $C$. arietinum. A gradual increase in root and shoot biomass of $M$. ciceri BRM5-inoculated plants treated with different doses of KITZ was observed both at 80 and 120 DAS. M. ciceri BRM5 maximally increased root, shoot and total dry biomass by 12,17 and $18 \%$, (at 80 DAS)

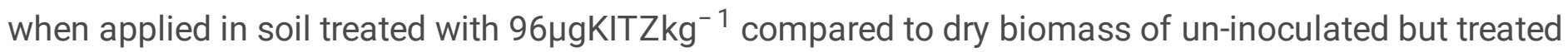
with the same dose of KITZ (Table S3, Fig. 4 panel e). There was a significant $(p \leq 0.05)$ interaction between application of symbiotic

bacterium and fungicide. The effect of bio-priming and fungicide on biological and chemical characteristics of test plants was significantly correlated both at 80 DAS and 120 DAS as revealed by regression analysis and principal component analysis (PCA) (Fig. S1 and S2).

\subsubsection{Bio-inoculation Impact of $M$. ciceri on Photosynthetic Molecules}

The effect of varying concentrations of KITZ on photosynthetic pigments of $C$. arietinum in the presence of $M$. ciceri BRM5 at 80 DAS was variable. On comparing the effect of the $1 \mathrm{X}$ concentration of KITZ on inoculated and non-inoculated plants, a maximal increases of $14 \%\left(0.28 \mathrm{mgg}^{-1}\right), 11 \%\left(0.28 \mathrm{mgg}^{-1}\right), 5 \%$ $\left(0.40 \mathrm{mgg}^{-1}\right)$ and $9 \%\left(1.21 \mathrm{mgg}^{-1}\right)$ in $\mathrm{Chl} \mathrm{a}, \mathrm{Chl} \mathrm{b}$, total chlorophyll and carotenoids content, respectively, was noted in $M$. ciceri BRM5-inoculated $C$. arietinum plants over untreated and non-inoculated control plants (Table S3). Likewise, photosynthetic pigments of $C$. arietinum plants improved following the inoculation of pesticide-tolerant PGPR strains. In this context, enhanced symbiotic performance and productivity of Phaseolus vulgaris in harsh environmental conditions was observed following the inoculation of tolerant native PGPR (Yanni et al., 2016). Increased nodulation and seed yield in V. faba due to inoculation of Rhizobium has been reported (Kebeneand, 2017).

\subsubsection{Effect of $M$. ciceri on Symbiotic Features of $C$. arietinum}

\subsubsection{Nodulation: Nodule Numbers and Nodule Dry Biomass}

The roots detached from un-inoculated and KITZ treated $C$. arietinum showed the poorly developed root system and weak/unhealthy nodular systems. In contrast, a better root system having healthy and more pink-colored showing wavy margin was recorded in bio-inoculated C. arietinum plant (Fig. 5 panel a, b). Generally, the symbiotic attributes [nodule number (NN) and nodule dry biomass (NDB)] of $M$. ciceri BRM5 bacterized $C$. arietinum plants grown in the presence of KITZ was greater compared to those recorded for un-inoculated plants supplemented with the identical dose of fungicide. $M$. ciceri BRM5 maximally increased NN and NDB by $23 \%$ and $22 \%$ at 80 DAS and $16 \%$ and $14 \%$, respectively at 120 DAS 


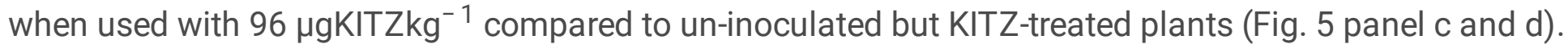
Ullah et al. (2016) also reported that PGPR strains in combination with M. ciceri increased the growth and nodulation of $C$. arietinum even in pesticide-stressed conditions.

\subsubsection{Leghaemoglobin (LHb) Content and nutrient uptake in nodule}

The $\mathrm{LHb}$ content in fresh nodules of $C$. arietinum declined in the presence of symbiotic bacteria similar to that in plants grown in fungicide only-supplemented soils. A considerable

Figure.5: Bio-inoculation impact of $M$. ciceri BRM5 on symbiotic features of $C$. arietinum plants; attachment of nodules with inoculated and treated roots (panel a), morphology of nodule (panel b) nodule number (panel c), nodule dry biomass (panel $d$ ) and LHb content (panel e) and nutrient uptake in nodules (panel f) grown in sandy clay loam soil treated with 96 (1X), $192(2 \mathrm{X})$ and $288(3 \mathrm{X}) \mu \mathrm{gKTZ \textrm {kg } ^ { - 1 }}$ soil and harvested at different intervals. The bar and line diagrams represent the mean \pm S.D $(n=3)$ of three replicates where each replicate constituted three plants/pot. Mean values followed by different letters are significantly different at $p \leq 0.05$ according to DMRT test.

improvement in LHb content of bacterized plants was, however, observed at 80 DAS relative to plants grown in the pesticide-only treatment. M. ciceriBRM5 significantly $(p \leq 0.05)$ and maximally enhanced $\mathrm{LHb}$ content by $21 \%$ [(0.34 to $\left.0.43 \mathrm{mM}(\mathrm{gfw})^{-1}\right]$ at $96 \mu \mathrm{gKITZkg}^{-1}$ over LHb content of un-inoculated but KITZ-treated plants (Fig. 5 panel e). Furthermore, the nutritional uptake in nodule was assessed was and it was recorded that $\mathrm{N}$ and $\mathrm{P}$ was maximally increased by $M$. ciceri when root systems were detached from plants treated with $1 \mathrm{X}$ dose of KITZ (Fig. 5 panel f).

\subsubsection{Impact of M. ciceri on Grain Attributes and Nutrient Uptake of C. arietinum}

\subsubsection{Seed Yield (SY) and Grain Protein}

Number of seeds, yield and grain protein of $C$. arietinum declined significantly in the presence of varying doses of KITZ. In contrast, seed yield (SY) of M. ciceri BRM5-inoculated $C$. arietinum plants improved significantly $(p \leq 0.05)$ in the presence of different doses of KITZ. A maximum increase of $13 \%, 15 \%, 11 \%$ and $6 \%$ in pod number, pod weight, seed number and seed yield was recorde when M. ciceri BRM5 was used with $96 \mu \mathrm{gKITZkg}^{-1}$ soil over un-inoculated but pesticide-treated control (Fig. 6 panel a and b). Likewise, BRM 5 increased the grain protein by $7 \%$ when used with the $1 \mathrm{X}$ dose of KITZ compared to uninoculated plants treated with the identical dose of fungicide (Fig. 6 panel c). The decrease in protein content of grain is likely be due to the binding of pesticides to R-SH groups of proteins which, in turn, alters protein structure. However, seed features of $C$. arietinum were generally improved following inoculation with M. ciceri BRM5 even in the presence of pesticide. R. leguminosarum strain PS1, when 
used as bio-inoculant in pesticide-treated pea plants, increased SY by $43 \%$ compared with fungicidetreated but un-inoculated plants (Tariq et al., 2016). Enhancement in growth attributes and yield of atrazine-treated Phaseolus vulgaris when grown in the presence of a consortium containing Rhizobium sp. and Trichoderma have been reported (Madariaga-Navarrete et al., 2017). Similar improvements in growth and nutrient levels were observed when stress-resistant PGPR strains of $P$. aeruginosa and Burkholderia gladioli were were applied to plants grown under stressed conditions (Khanna et al., 2019).

\subsubsection{Nutrient Uptake}

Bio-inoculation impact of $M$. ciceri BRM5 on $\mathrm{N}$ and $\mathrm{P}$ content of $C$. arietinum plant organs at $80 \mathrm{DAS}$ differed in a concentration-dependent manner. The $\mathrm{N}$ content in $C$. arietinum roots increased from 20.6 to $22.6 \mu \mathrm{g} \mathrm{g}^{-1}$ whereas in shoot tissue it increased from 11.5 to $13.3 \mu \mathrm{g} \mathrm{g}^{-1}$ when $M$. ciceri BRM5 was used in the presence of $96 \mu \mathrm{gKITZkg}^{-1}$ (Fig. 6 panel d). Similarly, M. ciceri BRM5 at $96 \mu \mathrm{gKTZkg}^{-1}$ soil improved root and shoot $\mathrm{P}$ by 7 and $11 \%$, respectively, compared to non-inoculated plants treated with similar concentrations of KTZ (Fig. 6 panel e). Uptake of nutrients ( $N$ and $P$ ) by $C$. arietinum raised in pesticide-enriched soils was also enhanced following inoculation with fungicide-tolerant symbiotic bacteria. In a similar study, ACC deaminase positive PGPR strains Pseudomonas brassicacearum Am3, $P$. marginalis Dp1 and Rhodococcus sp. Fp2 were found to improve growth and uptake of both major and trace nutrients viz., N, P, K, Ca, S and Fe in different varieties of legumes raised in stressed soils (Safronova et al., 2006). In another study, Phaseolus vulgaris plants inoculated with stress-tolerant PGPR belonging to a group of phosphate-solubilizing bacteria significantly lowered electrolyte leakage, LPO level, SOD, hydrogen peroxide and proline phosphatase activities and improved physio-biochemical attributes, nutrient uptake, and protein and carbohydrate content by relieving the stress (Rady et al., 2019).

\subsubsection{Proline, MDA and Antioxidant Enzymes 3.5.7.1 Proline and MDA Content}

The BRM5-inoculated $C$. arietinum plants had low levels of proline, MDA and antioxidant enzyme activity in organs even in the presence of different concentrations of KITZ. In general, strain BRM5 minimized the proline level even in the presence of fungicide. M. ciceri BRM5 significantly $(p \leq 0.05)$ and maximally reduced the proline content in roots, shoots and seeds by $27 \%, 26 \%$ and $33 \%$ at the $1 \mathrm{X}$ dose of KITZ (Fig. 7 panel $a$ and b) compared to un-inoculated plants treated with the identical dose of fungicide. Similarly, it was observed that M. ciceri BRM5 reduced the MDA content from 5.4 to $3.07 \mu$ moles g $\mathrm{g}^{-1} \mathrm{fw}$ compared to un-inoculated plants treated with $96 \mathrm{\mu gKITZkg}^{-1}$ (Fig. 7 panel c). Information is lacking as to how and why proline levels decline in legumes bio-inoculated with pesticide-tolerant PGPR and raised in pesticide-contaminated soil. The accumulation of proline declined significantly $(p \leq 0.05)$ in bio-primed $C$. arietinum grown in soil supplemented with high doses of pesticide. A similar reduction in proline content in foliage was recorded following inoculation of three phosphate-solubilizing strains of Pseudomonas (Pseudomonas sp. P. putida and P. fulva) under chlorpyrifos and pyriproxyfen stress (Munir et al., 2019). The bio-inoculation impact on MDA level in the presence of higher doses of KITZ 
varied considerably among the bacterial species. In another study, inoculation of plants with P. putida caused substantial reduction in lipid peroxidation biomarkers, MDA content and electrolyte leakage and gradually improved chlorophyll, carotenoid and carbohydrate contents and growth of plants under norflurazon (herbicide)-stressed conditions (Bourahla et al., 2018). Fungicide-tolerant M. ciceri BRM5 used in this study resulted in a significant decrease in MDA concentrations in pesticide-stressed $C$. arietinum plants. The inoculant ameliorated pesticide pressure, relieved oxidative damage in plants and allowed them to grow pesticide-polluted soil. These results indicate that the bacterial strains could serve in bioremediation strategies which lead to overall improvement in performance of leguminous crops while being cultivated under pesticide stress.

\subsubsection{Antioxidant Enzymes}

Antioxidant enzymes of $C$. arietinum foliage treated with different doses of KITZ decreased substantially in the presence of bacterial inoculants. CAT activity of $C$. arietinum foliage was reduced maximally and significantly $(p \leq 0.05)$ by $(8.3 \%)$ by $M$. ciceri BRM5 in the presence of $96 \mathrm{KTZ}_{\mathrm{Kgkg}}{ }^{-1}$ soil (Fig. 7 panel d). Similarly, bacterial strains maximally lowered the POD activity by $21 \%$ (from 2.78 to $2.2 \mu \mathrm{mol} \mathrm{min}^{-1} \mathrm{mg}^{-}$ $1 \mathrm{fw}$ ) in the foliage system when detached from $1 X$ concentration of KITZ (Fig. 7 panel d). Likewise, the APX and GPX activities of $C$. arietinum were increased by $19.6 \%$ (from 2.09 to $1.68 \mu \mathrm{mol} \mathrm{min}^{-1} \mathrm{mg}^{-1} \mathrm{fw}$ and $9 \%$ (from 0.99 to $0.90 \mu \mathrm{mol} \mathrm{min}{ }^{-1} \mathrm{mg}^{-1} \mathrm{fw}$ respectively at the $3 \mathrm{X}$ dose of KITZ following application of symbiotic bacterium (Fig. 7 panel e). In a similar study, strain SRB02 of B. aryabhattai considerably reduced levels of oxidative stress and antioxidant enzymes CAT, POD and SOD in soybean plants grown in stressed soil, and promoted overall growth of plants (Park et al., 2017). The declines in antioxidants due to inoculation with pesticide-tolerant bacterial strains consequently resulted in a substantial upsurge in overall growth of $C$. arietinum even under pesticide stress.

\subsubsection{Rhizosphere and Rhizoplane Colonization by Mesorhizobium under Stress}

Root colonization is a critical initial component of plant-microbe interaction in the plant rhizosphere. This mutualistic interaction is helpful in growth and development of plants as well as in protecting the crops from various biotic and abiotic insults (Verma et al., 2018). Considering this, halotolerant PGPR strain $M$. ciceri was checked for its root colonizing ability using SEM in the absence (Fig. 8A) and presence of KITZ (Fig. 8B). SEM images revealed that fungicide-untreated roots resulted in dense/compact colonization whereas treated roots showed lesser bacterial populations. Similar colonization of bacteria on $C$. arietinum root surfaces and consequent increase in plant growth was reported by other workers (Alekhya and

Figure. 7: Bio-inoculation impact of $M$. ciceri BRM5 on proline content (panel a) antioxidant enzymes: GPX (panel b), APX (panel c) CAT (panel d) and MDA content (panel e) of $C$. arietinum plants grown in

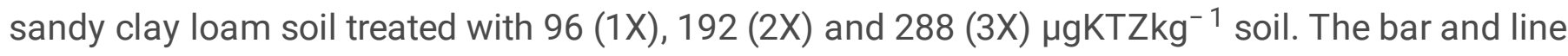
diagrams represent the mean \pm S.D $(n=3)$ of three replicates where each replicate constituted three 
plants/pot. Mean values followed by different letters are significantly different at $p \leq 0.05$ according to DMRT test.

Gopalakrishnan 2017; Wheatley and Poole, 2018; del Gallo et al. 2017). Bacterial components such as EPS, cell wall polysaccharides and extracellular bacterial proteins can provide for attachment onto the root surface. Bacterial counts from the rhizosphere and rhizoplane at varying intervals of seeding, i.e., 80 and 120 DAS with different doses of KITZ, were determined. The CFU counts were significantly reduced over untreated control with increasing level of fungicide; however, strain BRM5 survived and colonized even at the higher dose of fungicide. The lower doses imparted lesser impacts on viable counts of bacteria. At $3 \mathrm{X} \mathrm{KITZ,} \mathrm{the} \mathrm{rhizospheric} \mathrm{CFU} \mathrm{count} \mathrm{of} \mathrm{M.} \mathrm{ciceri} \mathrm{was} 3.2$ and $4.3 \mathrm{log} \mathrm{CFU} / \mathrm{mL}$ as compared to 6.7 and $5.1 \mathrm{log} \mathrm{CFU} / \mathrm{mL}$ (untreated control) at 80 DAS and 120 DAS, respectively (Fig. 8C). Similarly, viable populations of rhizoplane bacteria had declined over the untreated control. As PGPR colonize root surfaces, they multiply and reproduce by receiving key signalling compounds and nutrients from root exudates which subsequently leads to biofilm formation on the root system, a prominent indicator of successful plant-microbe interaction.

\section{Conclusion}

Fungicide applied in the study detrimentally affected the germinative ability of $C$. arietinum leading to the decrease in plant growth parameters as recorded both under in vitro and soil system. M. ciceri could tolerate higher level of kitazin and synthesized growth regulating bioactive molecules even in fungicide supplemented media. Following application to soil, $M$. ciceri improved performance of $C$. arietinum and enhanced dry biomass production, yield, symbiosis and leaf pigments even in a fungicide-polluted environment. Additionally, pesticide-tolerant nodule bacterium M. ciceri declined the stressor metabolites and antioxidant status of plant. The present study creates a new perspective for understanding the mechanistic basis of declines in stressor molecules and antioxidant defense enzymes in symbiotic bacterium-inoculated $C$. arietinum grown in fungicide-contaminated soil. Furthermore, symbiotic strain effectively colonized the plant rhizosphere/rhizoplane. Conclusively, in pesticide- contaminated soils, inoculation of $M$. ciceri may serve as an excellent strategy for augmenting $C$. arietinum productivity.

\section{Declarations}

\section{Acknowledgment}

All the authors extend their appreciation to Professor John Pichtel, (PhD, CHMM, Environment, Geology and Natural Resources Ball State University Muncie, IN 47306). Authors are highly thankful to Prof. J. Pichtel for critically examining and improving the English as well as scientific language of the manuscript. The corresponding author also acknowledges the University grant commission India (UGC) for financial support in the form of UGC-Non NET fellowship. 


\section{Compliance with ethical standards}

\section{Funding:}

There is no any source of funding for the present study.

\section{Conflict of interest}

All authors have declared there is no conflict of interest

\section{Credit Author Statement}

M.S performed the experiment, statistically analyzed the data and prepared the draft of the manuscript. M.S.K, supervised, designed, corrected and improved the original draft of the manuscript. All the authors revised and approved the final version of manuscript.

\section{Data availability.}

The datasets generated during and/or analyzed during the current study are available from the corresponding author on reasonable request.

\section{References}

1. Adami, M.F.F., Modolo, A.J.E., Adami, P.F., 2017. White clover tolerance to herbicides applied at different rates and phenological stages. African Journal of Agricultural Research 12, 2336-2341.

2. Ahemad, M, Khan, M.S., 2012. Effects of pesticides on plant growth promoting traits of Mesorhizobium strain MRC4. Journal of Saudi Society of Agricultural Sciences 11: 63-71.

3. Ahmed, B., Shahid, M., Khan, M.S., Musarrat, J., 2018. Chromosomal aberrations, cell suppression and oxidative stress generation induced by metal oxide nanoparticles in onion (Allium cepa) bulb. Metallomics 10: 1315-1327.

4. Alekhya, G., Gopalakrishnan, S., 2017. Biological control and plant growth-promotion traits of Streptomyces species under greenhouse and field conditions in chickpea. Agricultural Research6: 410-420.

5. Alori, E.T., Glick, B.R., Babalola, O.O., 2017. Microbial phosphorus solubilization and its potential for use in sustainable agriculture. Frontiers in Microbiology 8: 1-8.

6. Angelin, J., Kavitha, M., 2020. Exopolysaccharides from probiotic bacteria and their health potential. International Journal of Biological Macromolecules. 
7. Arnon, D.I., 1949. Copper enzymes in isolated chloroplasts. Polyphenol oxidase in Beta vulgaris. Applied and Environmental Microbiology 55: 1665-1669.

8. Aroua, I., Abid, G., Souissi, F., Mannai, K., Nebli, H., Hattab, S., Borgi, Z. and Jebara, M., 2019. Identification of two pesticide-tolerant bacteria isolated from Medicago sativa nodule useful for organic soil phytostabilization. International Microbiology22: 111-120.

9. Bakker, A.W., Schippers, B., 1987. Microbial cyanide production in the rhizosphere in relation to potato yield reduction and Pseudomonas-mediated plant growth-stimulation. Soil Biology and Biochemistry 19: 451-457.

10. Bates, L.S., Woldren, R.P., Teare, I.D., 1973 Rapid determination of free proline for water stress studies. Plant and Soil 39: 205-208.

11. Belimov, A.A., Dodd, I.C., Safronova, V.I., Shaposhnikov, A.I., Azarova, T.S., Makarova, N.M., Davies, W.J. and Tikhonovich, I.A., 2015. Rhizobacteria that produce auxins and contain 1-aminocyclopropane-1-carboxylic acid deaminase decrease amino acid concentrations in the rhizosphere and improve growth and yield of well-watered and water-limited potato (Solanum tuberosum). Annals of Applied Biology167: 11-25.

12. Bourahla, M., djebbar, R., Kaci, Y. and Abrous-Belbachir, O., 2018. Alleviation of bleaching herbicide toxicity by PGPR strain isolated from wheat rhizosphere. Analele Universitatii din Oradea, Fascicula Biologie, 25(2).

13. Brick, J.M., Bostock, R.M., Silverstone, S.E., 1991. Rapid in situ assay for indole acetic acid production by bacteria immobilized on a nitrocellulose membrane. Applied Environmental Microbiology 57: 535-538.

14. Cortés-Eslava, J., Gómez-Arroyo, S., Risueño, M.C., Testillano, P.S., 2018. The effects of organophosphorus insecticides and heavy metals on DNA damage and programmed cell death in two plant models. Environmental Pollution 240: 77-86.

15. del Gallo, M., Ercole, C., Matteucci, F., 2017. Plant-bacteria interaction at the microscope. In: MéndezVilas A (ed) Microscopy and imaging science: practical approaches to applied research and education, 312-31.

16. Dye, D.W., 1962. The inadequacy of the usual determinative tests for the identification of XanthomonasNew Zealand Journal of Science 5: 393-416.

17. Eker, S., Ozturk, L., Yazici, A, Erenoglu, B., Romheld, V., Cakmak, I., 2006. Foliar-applied glyphosate substantially reduced uptake and transport of iron and manganese in sunflower (Helianthus annuus) plants. Journal of Agriculture and food Chemistry 54: 10019-10025.

18. El-Ghany, A., Mona, F. and Attia, M., 2020. Effect of exopolysaccharide-producing bacteria and melatonin on faba bean production in saline and non-saline soil. Agronomy10: 316.

19. Fatima, T., Mishra, I., Verma, R. and Arora, N.K., 2020. Mechanisms of halotolerant plant growth promoting Alcaligenes involved in salt tolerance and enhancement of the growth of rice under salinity stress. 3 Biotech, 10: 1-12. 
20. Gage, D.J., 2004. Infection and invasion of roots by symbiotic, nitrogen-fixing rhizobia during nodulation of temperate legumes. Microbiology and Molecular Biology Reviews, 68, 280-300.

21. Ghosh, D., Gupta, A., Mohapatra, S., 2019. A comparative analysis of exopolysaccharide and phytohormone secretions by four drought-tolerant rhizobacterial strains and their impact on osmoticstress mitigation in Arabidopsis thaliana. World Journal of Microbiology and Biotechnology, 35, 90.

22. Gill, S.S., Tuteja, N., 2010. Reactive oxygen species and antioxidant machinery in abiotic stress tolerance in crop plants, Plant Physiology and Biochemistry 48: 909-930.

23. Gothandapani, S., Sekar, S., Padaria, J.C., 2017. Azotobacter chroococcum: Utilization and potential use for agricultural crop production: An overview. International Journal of Advanced Research in Biological Sciences 4, 35-42.

24. Gurikar, C., Naik, M.K., Sreenivasa, M.Y., 2016. Azotobacter. PGPR activities with special reference to effect of pesticides and biodegradation. In: Microbial inoculants in sustainable agricultural productivity 229-244 Springer, India

25. Hammerschmidt, R., Nuckles, E.M. and Kuć, J., 1982. Association of enhanced peroxidase activity with induced systemic resistance of cucumber to Colletotrichum lagenarium. Physiological Plant Pathology, 20, 73-82.

26. Han, L., Liu, Y., Fang, K., Zhang, X., Liu, T., Wang, F. and Wang, X., 2020. Dissipation of chlorothalonil in the presence of chlortetracycline and ciprofloxacin and their combined effects on soil enzyme activity. Environmental Science and Pollution Research 1-8.

27. Hang, P., Zhang, L., Zhou, X.Y., Hu, Q. and Jiang, J.D., 2019. Rhizobium album nov., isolated from a propanil-contaminated soil. Antonie Van Leeuwenhoek, 112, 319-327.

28. Holt, G.J., Krieg, N.R., Sneath, P.H.A., 1994. Gram negative aerobic/microaerophilic rods and cocci. In: Bergey's manual of determinative bacteriology, 9th edn. Williams and Wilkins, Lippincott, Philadelphia.

29. Honma, M. and Shimomura, T., 1978. Metabolism of 1-aminocyclopropane-1-carboxylic acid. Agricultural and Biological Chemistry, 42, 1825-1831.

30. Jaiswal, D.K., Verma, J.P., Krishna, R., Gaurav, A.K. and Yadav, J., 2019. Molecular characterization of monocrotophos and chlorpyrifos tolerant bacterial strain for enhancing seed germination of vegetable crops. Chemosphere223, 636-650.

31. Kang, J.P., Huo, Y., Yang, D.U. and Yang, D.C., 2020. Influence of the plant growth promoting Rhizobium panacihumi on aluminum resistance in Panax ginseng. Journal of Ginseng Research

32. Khan, S., Shahid, M., Khan, M.S., Syed, A., Bahkali, A.H., Elgorban, A.M. and Pichtel, J., 2020. Fungicide-tolerant plant growth-promoting rhizobacteria mitigate physiological disruption of white radish caused by fungicides used in the field cultivation. International Journal of Environmental Research and Public Health, 17: 7251.

33. Khanna, K., Jamwal, V.L., Kohli, S.K., Gandhi, S.G., Ohri, P., Bhardwaj, R., Abd_Allah, E.F., Hashem, A. and Ahmad, P., 2019. Plant growth promoting rhizobacteria induced $\mathrm{Cd}$ tolerance in Lycopersicon esculentum through altered antioxidative defense expression. Chemosphere217, 463-474. 
34. Kirk, J.T.O., Allen, R.L., 1965. Dependence of chloroplast pigment synthesis on protein synthesis: effect of actidione. Biochemical and Biophysical Research Communication 21, 523-530.

35. Kumar, N., Bora, A., Kumar, R., Amb, M.K., 2012. Differential effects of agricultural pesticides endosulfan and tebuconazole on photosynthetic pigments, metabolism and assimilating enzymes of three heterotrophic, filamentous cyanobacteria. Journal of Biological and Environmental Science 6: 67-75.

36. Kumar, G., Pandey, A., 2015. Heavy metal induced genomic distortion in root meristems of coriander (Coriandrum sativum). International Journal of Research Plant Sciences, 4, 47-53.

37. Kumar, M., Yusuf, M.A., Chauhan, P.S., Nigam, M. and Kumar, M., 2017. Pseudomonas putida and Bacillus amyloliquefaciens alleviates the adverse effect of pesticides and poise soil enzymes activities in chickpea (Cicer arietinum) rhizosphere. Tropical Plant Research 4, 405-418.

38. Lang, Z., Qi, D., Dong, J., Ren, L., Zhu, Q., Huang, W., Liu, Y., Lu, D., 2018. Isolation and characterization of a quinclorac-degrading Actinobacteria Streptomyces strain AH-B and its implication on microecology in contaminated soil. Chemosphere 199, 210-217

39. Lastochkina, O., Pusenkova, L., Yuldashev, R., Babaev, M., Garipova, S., Blagova, D.Y., Khairullin, R., Aliniaeifard, S., 2017. Effects of Bacillus subtilis on some physiological and biochemical parameters of Triticum aestivum (wheat) under salinity. Plant Physiology and Biochemistry 121: 80-88.

40. Leonard, S.S., Harris, G.K. and Shi, X., 2004. Metal-induced oxidative stress and signal transduction. Free Radical Biology and Medicine, 37, 1921-1942.

41. Lindner, R.C., 1944. Rapid analytical methods for some of the more common inorganic constituents of plant tissues. Plant Physiology 19: 76

42. Liu, J.L., Yu, J.F., Yin, J.L. and WU, J.C., 2006. Research progress on the effect of chemical pesticides on plant physiology and biochemistry. Pesticide-Shenyang, 45, 511.

43. Lowry, O.H., Rosebrough, N.J., Farr, A.L. and Randall, R.J., 1951. Protein measurement with the Folin phenol reagent. Journal of Biological Chemistry, 193, 265-275.

44. Ma, L., Chen, S., Yuan, J., Yang, P., Liu, Y. and Stewart, K., 2017. Rapid biodegradation of atrazine by Ensifer sp. strain and its degradation genes. International Biodeterioration \& Biodegradation, 116, 133-140.

45. Madariaga-Navarrete, A., Rodríguez-Pastrana, B.R., Villagómez-lbarra, J.R., Acevedo-Sandoval, O.A., Perry, G. and Islas-Pelcastre, M., 2017. Bioremediation model for atrazine contaminated agricultural soils using phytoremediation (using Phaseolus vulgaris) and a locally adapted microbial consortium. Journal of Environmental Science and Health, Part B, 52, 367-375.

46. Matse, D.T., Huang, C.H., Huang, Y.M. and Yen, M.Y., 2020. Effects of coinoculation of Rhizobium with plant growth promoting rhizobacteria on the nitrogen fixation and nutrient uptake of Trifolium repens in low phosphorus soil. Journal of Plant Nutrition, 43, 739-752.

47. Mukherjee, P., Mitra, A. and Roy, M., 2019. Halomonas rhizobacteria of Avicennia marina of Indian Sundarbans promote rice growth under saline and heavy metal stresses through exopolysaccharide production. Frontiers in Microbiology10, 1207. 
48. Munir, I., Bano, A. and Faisal, M., 2019. Impact of phosphate solubilizing bacteria on wheat (Triticum aestivum) in the presence of pesticides. Brazilian Journal of Biology79, 29-37.

49. Niinemets, Ü. and Kull, O., 2001. Sensitivity of photosynthetic electron transport to photoinhibition in a temperate deciduous forest canopy: photosystem II center openness, non-radiative energy dissipation and excess irradiance under field conditions. Tree Physiology, 21,899-914.

50. Pacheco-Villalobos, D., Díaz-Moreno, S.M., van der Schuren, A., Tamaki, T., Kang, Y.H., Gujas, B., Novak, O., Jaspert, N., Li, Z., Wolf, S., Oecking, C., 2016. The effects of high steady state auxin levels on root cell elongation in Brachypodium. The Plant Cell, 28, 1009-1024.

51. Park, Y.G., Mun, B.G., Kang, S.M., Hussain, A., Shahzad, R., Seo, C.W., Kim, A.Y., Lee, S.U., Oh, K.Y., Lee, D.Y. and Lee, I.J., 2017. Bacillus aryabhattai SRB02 tolerates oxidative and nitrosative stress and promotes the growth of soybean by modulating the production of phytohormones. PLoS One, 12, 0173203.

52. Penrose, D.M. and Glick, B.R., 2003. Methods for isolating and characterizing ACC deaminasecontaining plant growth-promoting rhizobacteria. Physiologia Plantarum, 118, 10-15.

53. Rady, M.M., Elrys, A.S., El-Maati, M.F.A. and Desoky, E.S.M., 2019. Interplaying roles of silicon and proline effectively improve salt and cadmium stress tolerance in Phaseolus vulgarisPlant Physiology and Biochemistry 139, 558-568.

54. Rijavec, T., Lapanje, A., 2016. Hydrogen cyanide in the rhizosphere: not suppressing plant pathogens, but rather regulating availability of phosphate. Frontiers in Microbiology7, 1785.

55. Rodríguez-Navarro, D.N., Rodríguez-Carvajal, M.A., Acosta-Jurado, S., Soto, M.J., Margaret, I., CrespoRivas, J.C., Sanjuan, J., Temprano, F., Gil-Serrano, A., Ruiz-Sainz, J.E. and Vinardell, J.M., 2014. Structure and biological roles of Sinorhizobium fredii HH103 exopolysaccharide. PLoS One, 9, 115391.

56. Romdhane, S., Devers-Lamrani, M., Martin-Laurent, F., Calvayrac, C., Rocaboy-Faquet, E., Riboul, D., Cooper, J.F. and Barthelmebs, L., 2016. Isolation and characterization of Bradyrhizobium sp. SR1 degrading two $\beta$-triketone herbicides. Environmental Science and Pollution Research, 23, 4138-4148.

57. Roy, T., Bandopadhyay, A., Sonawane, P.J., Majumdar, S., Mahapatra, N.R., Alam, S. and Das, N., 2018. Bio-effective disease control and plant growth promotion in lentil by two pesticide degrading strains of Bacillus Biological Control, 127, 55-63.

58. Safronova, V.I., Stepanok, V.V., Engqvist, G.L., Alekseyev, Y.V. and Belimov, A.A., 2006. Root-associated bacteria containing 1-aminocyclopropane-1-carboxylate deaminase improve growth and nutrient uptake by pea genotypes cultivated in cadmium supplemented soil. Biology and Fertility of Soils, 42, 267-272.

59. Shahid, M., Khan, M.S., 2018. Glyphosate induced toxicity to chickpea plants and stress alleviation by herbicide tolerant phosphate solubilizing Burkholderia cepacia PSBB1 carrying multifarious plant growth promoting activities. 3 Biotech8, 118-131.

60. Shahid, M., Khan, M.S., 2019. Fungicide tolerant Bradyrhizobium japonicum mitigate toxicity and enhance greengram production under hexaconazole stress. Journal of Environmental Sciences78, 
92-108.

61. Shahid, M., Khan, M.S., Zaidi, A., 2020. Fungicide Toxicity to Legumes and Its Microbial Remediation: A Current Perspective. Pesticides in Crop Production: Physiological and Biochemical Action, 15-33.

62. Shahid, M., Khan, M.S., Ahmed, B., Syed, A. and Bahkali, A.H., 2020. Physiological disruption, structural deformation and low grain yield induced by neonicotinoid insecticides in chickpea: A long term phytotoxicity investigation. Chemosphere, 262, 128388.

63. Shahid, M., Zaidi, A., Ehtram, A. and Khan, M.S., 2019. In vitro investigation to explore the toxicity of different groups of pesticides for an agronomically important rhizosphere isolates Azotobacter vinelandii. Pesticide Biochemistry and Physiology157, 33-44.

64. Shahzad, B., Tanveer, M., Che, Z., Rehman, A., Cheema, S.A., Sharma, A., Song, H., ur Rehman, S. and Zhaorong, D., 2018. Role of 24-epibrassinolide (EBL) in mediating heavy metal and pesticide induced oxidative stress in plants: A review. Ecotoxicology and Environmental Safety, 147, 935-944.

65. Sijilmassi, B., Filali-Maltouf, A., Fahde, S., Ennahli, Y., Boughribil, S., Kumar, S. and Amri, A., 2020. Invitro plant growth promotion of Rhizobium strains isolated from lentil root nodules under abiotic stresses. Agronomy10, 1006.

66. Silambarasan, S. and Abraham, J., 2013. Kinetic studies on enhancement of degradation of chlorpyrifos and its hydrolyzing metabolite TCP by a newly isolated Alcaligenes JAS1. Journal of the Taiwan Institute of Chemical Engineers, 44, 438-445.

67. Singh, D. and Roy, B.K., 2017. Evaluation of malathion-induced cytogenetical effects and oxidative stress in plants using Allium Acta Physiologiae Plantarum, 39, 92.

68. Tang, J., Liu, B., Chen, T.T., Yao, K., Zeng, L., Zeng, C.Y. and Zhang, Q., 2018. Screening of a betacypermethrin-degrading bacterial strain Brevibacillus parabrevis BCP-09 and its biochemical degradation pathway. Biodegradation, 29, 525-541.

69. Tripathy, S.K., Bijayinee, S., Samad, I. and Das, R.K., 2013. Endosulfan: a potential genotoxicant on Allium cepa root tip cells. Journal of Agricultural Biotechnology and Sustainable Development, 5, 2935.

70. Ullah, S., Raza, M.S., Imran, M., Azeem, M., Awais, M., Bilal, M.S. and Arshad, M., 2016. Plant growth promoting rhizobacteria amended with Mesorhizobium ciceri inoculation effect on nodulation and growth of chickpea. Cicer arietinum, 3408-3420.

71. Verma, S.K., Kingsley, K., Bergen, M., English, C., Elmore, M., Kharwar, R.N. and White, J.F., 2018. Bacterial endophytes from rice cut grass (Leersia oryzoides) increase growth, promote root gravitropic response, stimulate root hair formation, and protect rice seedlings from disease. Plant and Soil, 422, 223-238.

72. Walia, A., Mehta, P., Guleria, S., Chauhan, A. and Shirkot, C.K., 2014. Impact of fungicide mancozeb at different application rates on soil microbial populations, soil biological processes, and enzyme activities in soil. The Scientific World Journal

73. Wheatley, R.M. and Poole, P.S., 2018. Mechanisms of bacterial attachment to roots. FEMS Microbiological Review42: 448-461. 
74. Xiao, Y.M., Esser, L., Zhou, F., Li, C., Zhou, Y.H., Yu, C.A., Qin, Z.H. and Xia, D., 2014. Studies on inhibition of respiratory cytochrome bc 1 complex by the fungicide pyrimorph suggest a novel inhibitory mechanism. Plos one, 9(4), p.e93765.

75. Yin, Y.L., Zhou, Y., Zhou, Y.H., Shi, K., Zhou, J., Yu, Y., Yu, J.Q. and Xia, X.J., 2016. Interplay between mitogen-activated protein kinase and nitric oxide in brassinosteroid-induced pesticide metabolism in Solanum lycopersicum. Journal of Hazardous Materials, 316, 221-231.

76. Zablotowicz, R.M. and Reddy, K.N., 2007. Nitrogenase activity, nitrogen content, and yield responses to glyphosate in glyphosate-resistant soybean. Crop Protection, 26, 370-376.

77. Zeyad, M.T., Kumar, M. and Malik, A., 2019. Mutagenicity, genotoxicity and oxidative stress induced by pesticide industry wastewater using bacterial and plant bioassays. Biotechnology Reports 24, 00389.

\section{Figures}



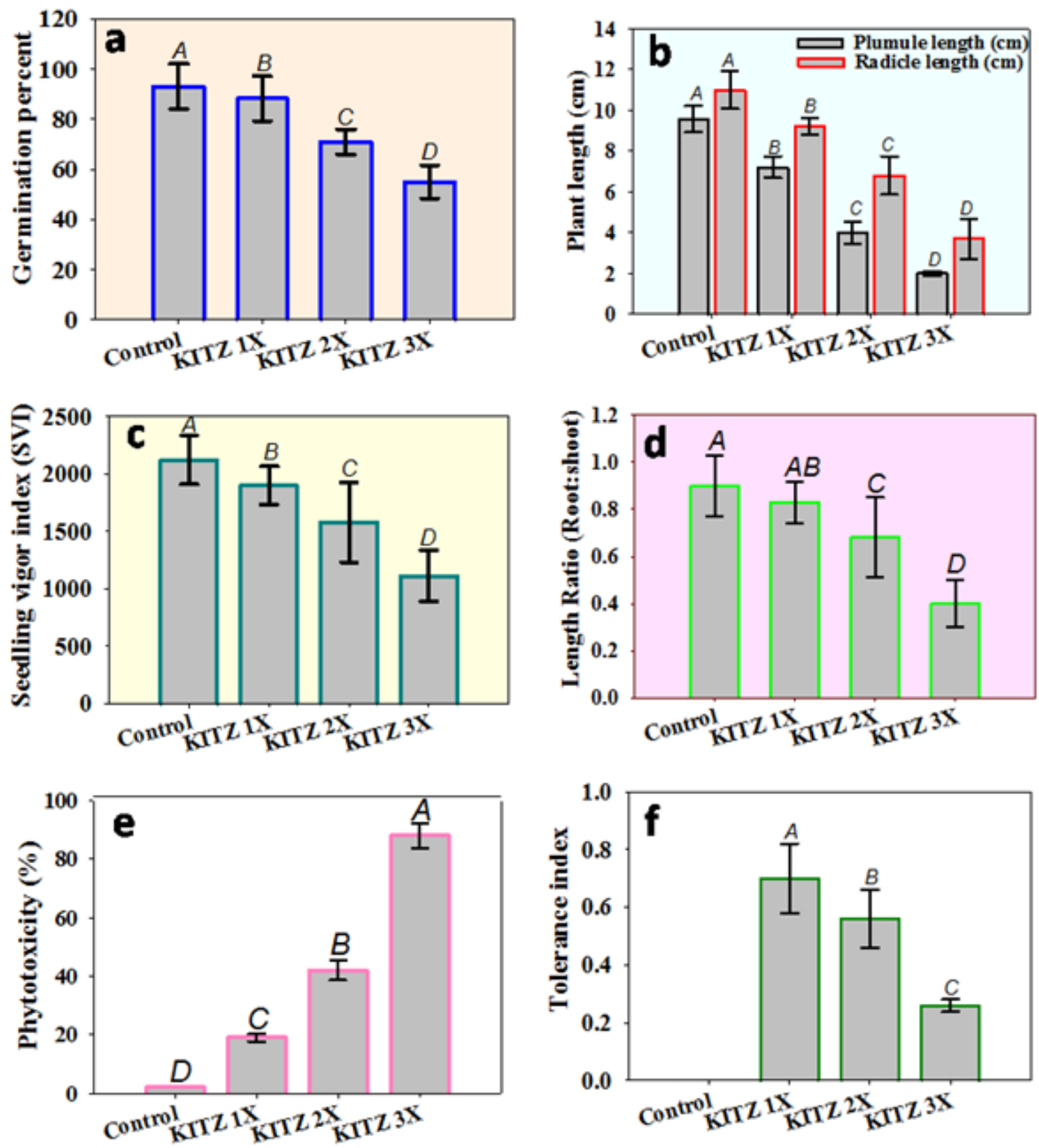

Figure 1

Effect of kitazin on germination percent (panel a), plant length (panel b) vigor index (panel c) root-shoot length ratio (panel d) percent phytotoxicity (panel e) and tolerance index (panel f) of Cicer arietinum seedlings geminated on $0.7 \%$ soft agar plates treated with three concentrations of KITZ under in vitro condition. Each bar represents the mean $\pm S . D(n=3)$ of three replicates where each replicate constituted three plants/pot. Mean values followed by different letters are significantly different at $p \leq 0.05$ according to Duncan's multiple range (DMRT) test whereas error bars represent standard deviation (S.D). 


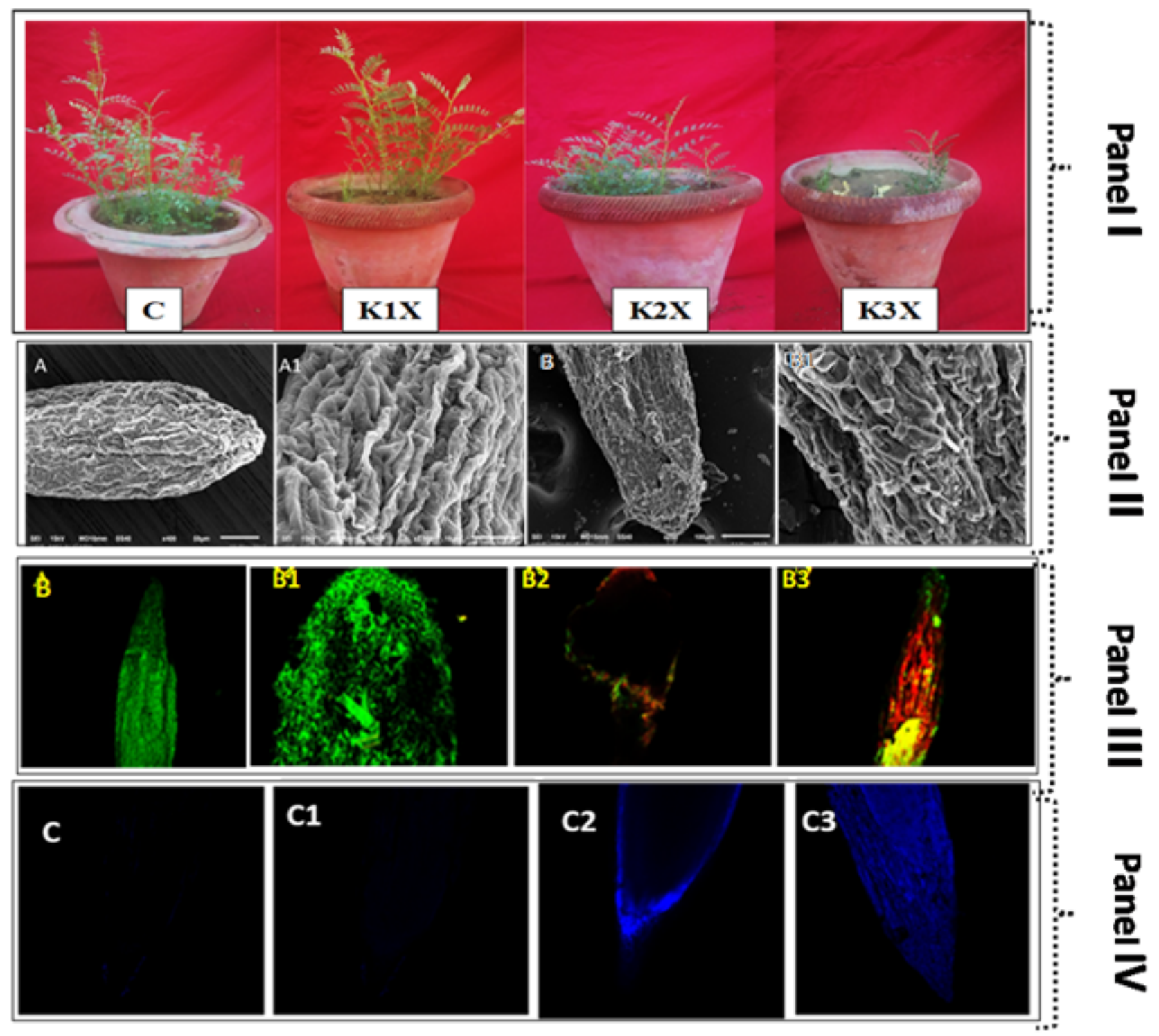

Figure 2

Effect of KITZ on C. arietinum plants grown with 96 (KITZ 1X), 192 (KITZ 2X) and 288 нgKITZkg-1 (KITZ 3X) soil (Panel I). Scanning electron microscopic (SEM) images of $C$. arietinum roots demonstrating distortion/damage induced by KITZ exposure: A and A1 represents the root tip and root surface of untreated/control. B and B1 represent the distorted/ruptured root tips and root tip surfaces treated with KITZ (Panel II). The Z-stack images of PI/AO stained C. arietinum roots using CLSM. Images reveal an increase in red/orange fluorescence as concentrations of KITZ increase. Untreated control root showing no red color (B), while roots treated with various doses of KITZ (B1, B2 and B3) (Panel III). The Z-stack image of chickpea using CLSM representing the cytotoxicity (Evans blue dye exclusion) assay in root tissues induced by fungicide. Figures show uptake of Evans blue dye by root cells; untreated control root showing no blue color (C), while $\mathrm{C} 1, \mathrm{C} 2$ and $\mathrm{C} 3$ represents the roots treated with various doses of KITZ (Panel IV). 

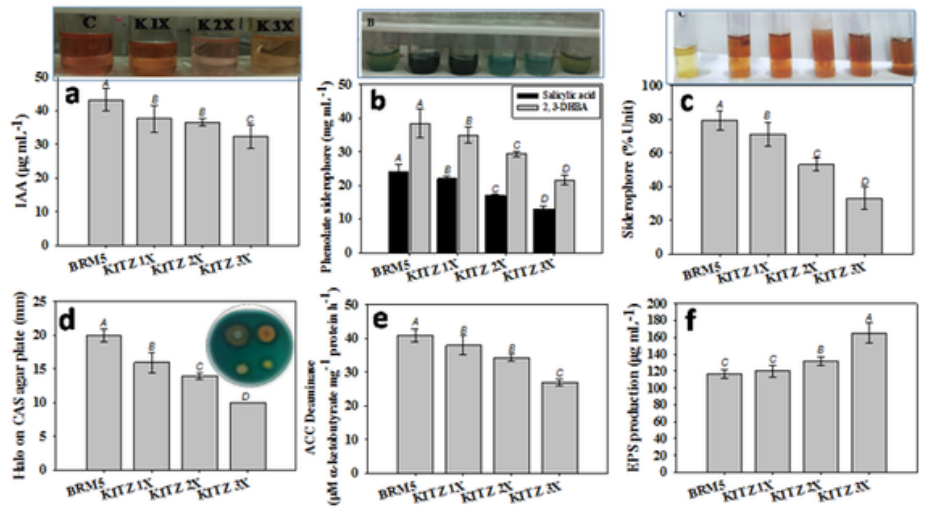

A
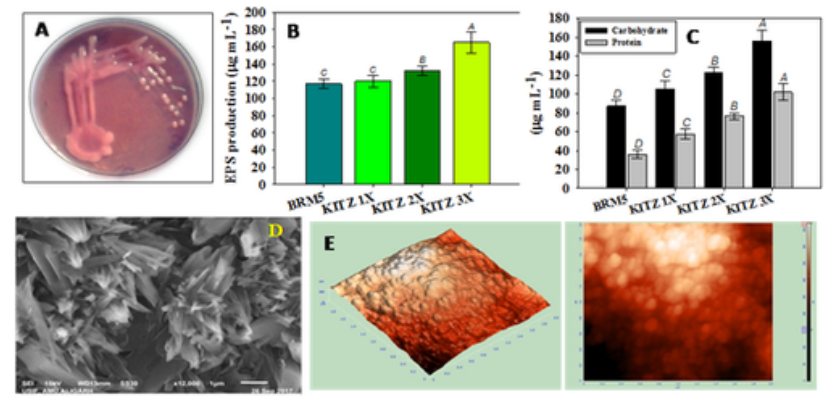

E
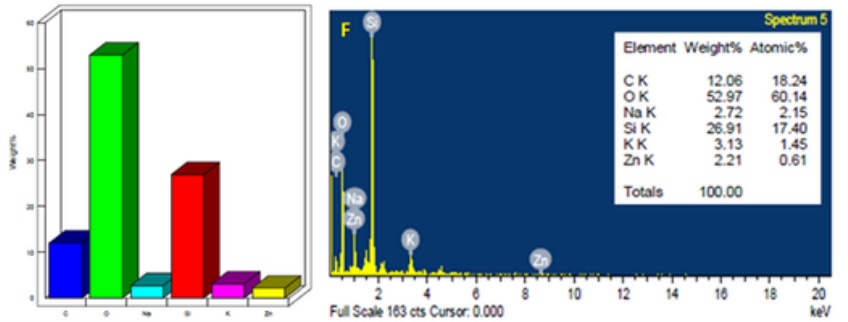

B

\section{Figure 3}

A) Plant growth regulating bioactive molecules; indole-3-acetic acid (panel a), phenolate type siderophore [salicylic acid and 2.3-DHBA) (panel b), siderophore \% unit (panel c), chrome azurol-S agar (panel d), ACC deaminase (panel e) and exopolysaccharide (panel f) produced by M. ciceri BRM5 in the absence and presence of different doses of KITZ. In this figure, bar diagrams represents the mean values (mean \pm S.D) of three independent replicate whereas, error bars depicts the standard deviation (S.D). Different letters on bars denotes that mean values are significantly different (at $p \leq 0.05)$ according to DMRT. B)

Exopolysaccharide (EPS) producing cultures of M. ciceri on YEMA plate (A), Bar diagrams represents the EPS synthesized by strain BRM5 in the presence of varying concentrations of KITZ (B), quantification of EPS; carbohydrate and protein content (C), morphological analysis of dried powder of EPS under SEM (D), topographical analysis of dried powder of EPS under Atomic force microscope (AFM) (E), EDX analysis of dried powder of EPS showing the presence of various elements $(F)$ 

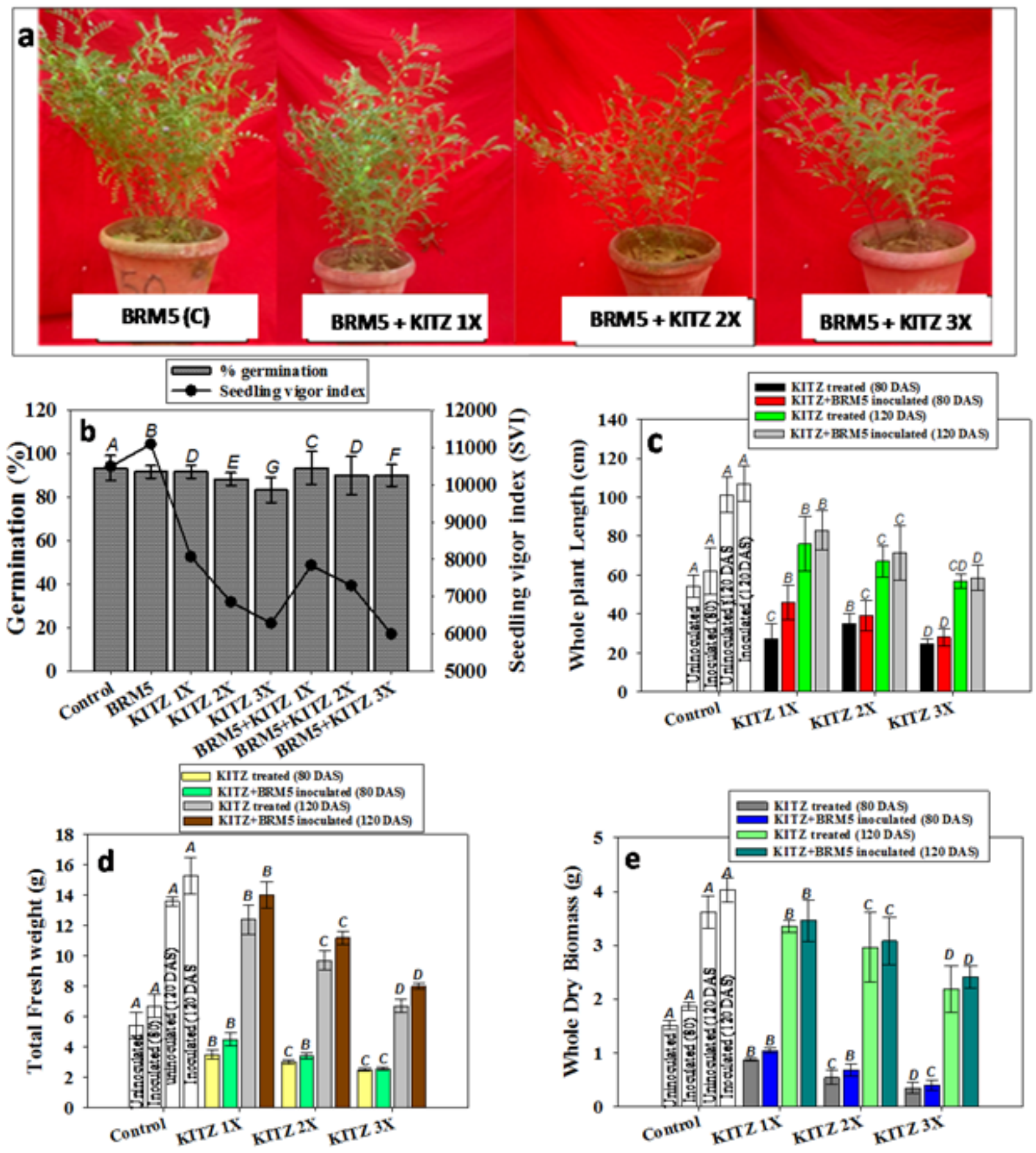

Figure 4

Inoculation impact of kitazin tolerant M. ciceri BRM5 on C. arietinum plants grown in sandy clay loam soil treated with 96 (1X), 192 (2X) and 288 (3X) $\mu \mathrm{gKITZkg-1} \mathrm{soil} \mathrm{developed} \mathrm{in} \mathrm{greenhouse} \mathrm{conditions}$ (panel a), germination efficiency and vigor index (panel b), total plant length (panel c) total fresh weight (panel d) and total dry biomass (panel e). The bar and line diagrams represent mean \pm standard deviation (S.D) $(n=3)$ of three replicates where each replicate constituted three plants/pot. Mean values followed by different letters are significantly different at $p \leq 0.05$ according to DMRT test. 


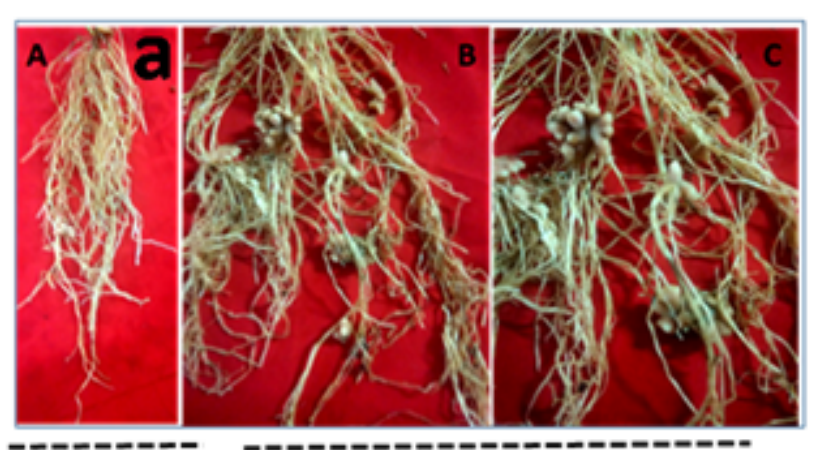

KTTZ treated
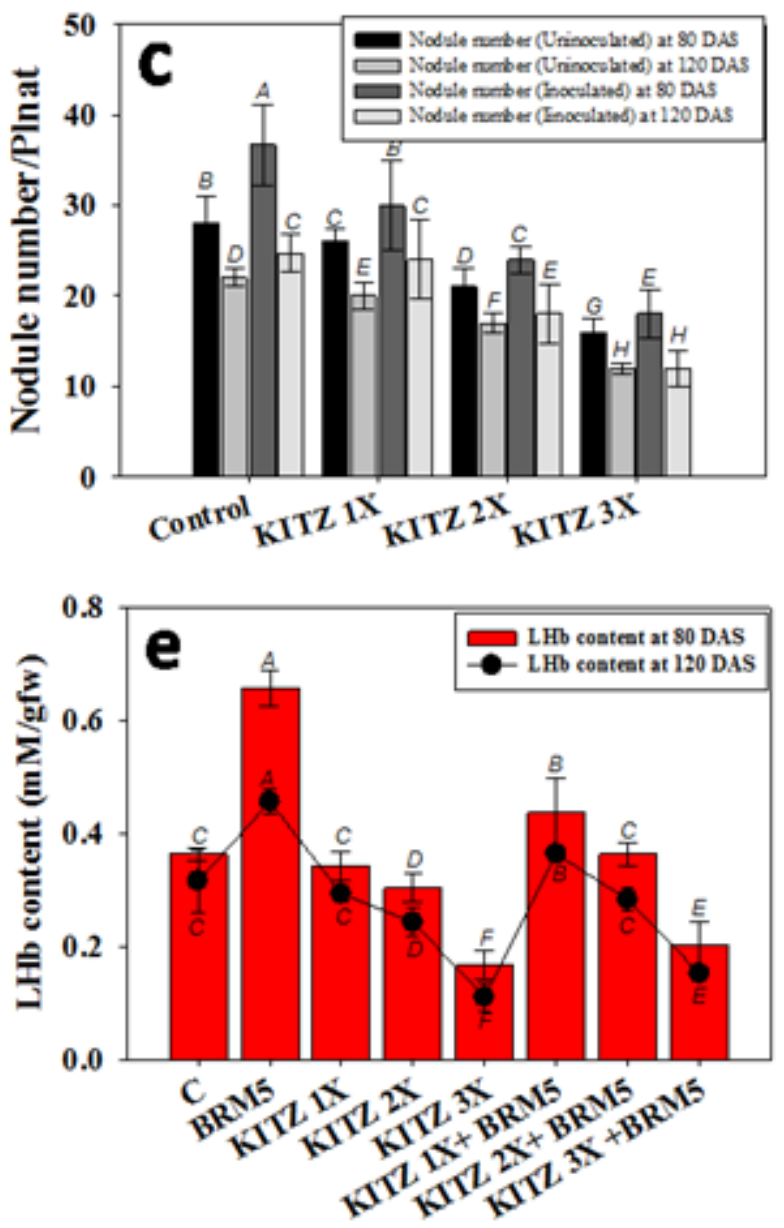

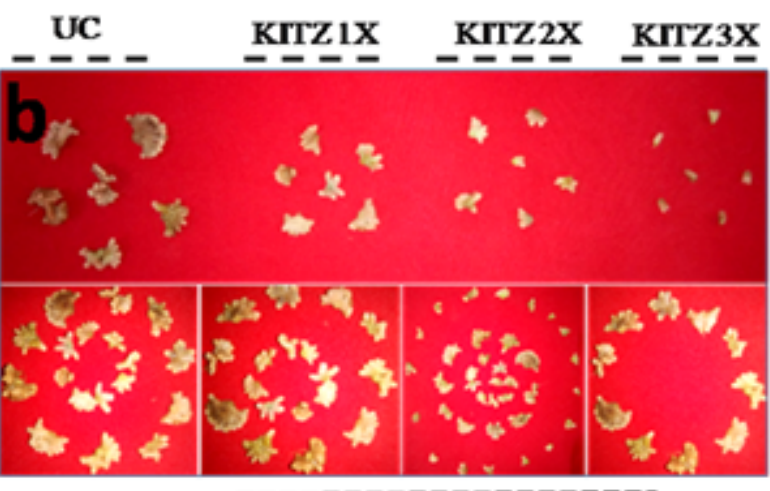

Inoculated and treated with KITZ
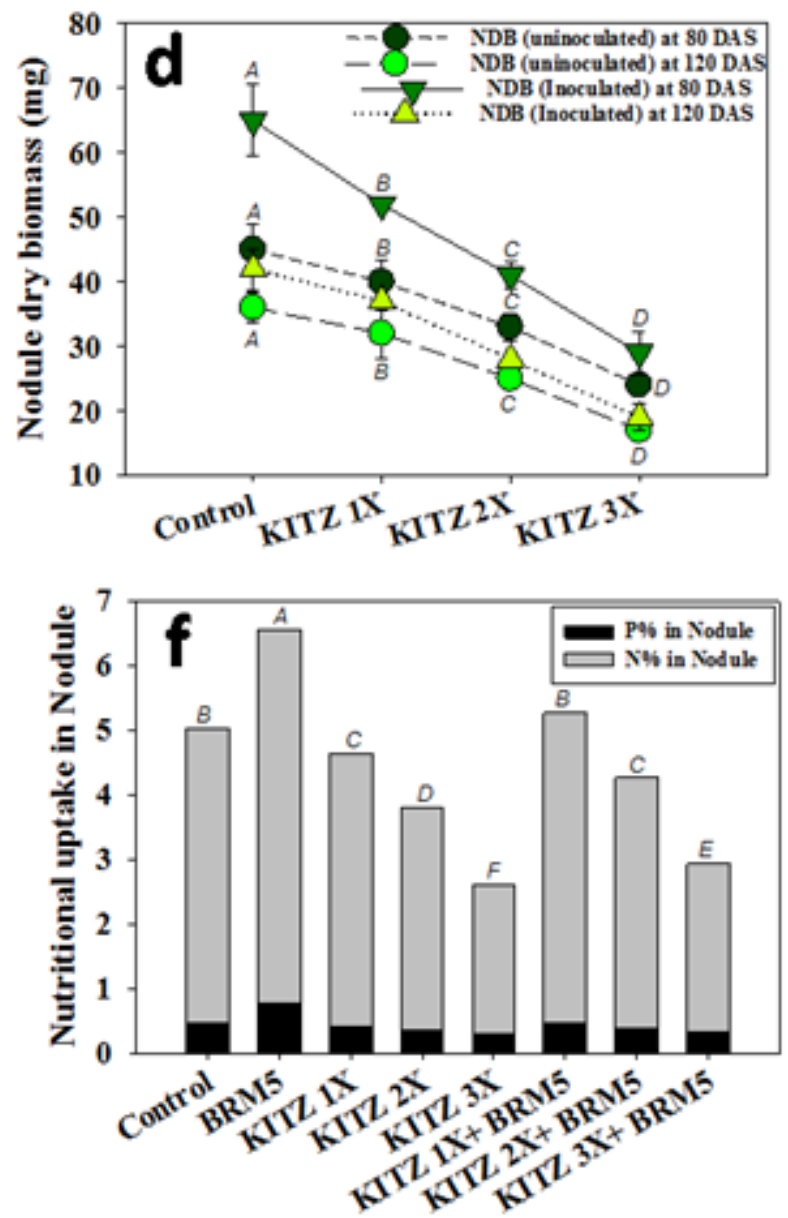

Figure 5

Bio-inoculation impact of M. ciceri BRM5 on symbiotic features of C. arietinum plants; attachment of nodules with inoculated and treated roots (panel a), morphology of nodule (panel b) nodule number (panel c), nodule dry biomass (panel d) and LHb content (panel e) and nutrient uptake in nodules (panel f) grown in sandy clay loam soil treated with 96 (1X), 192 (2X) and 288 (3X) $\mu \mathrm{gKTZkg-1}$ soil and harvested at different intervals. The bar and line diagrams represent the mean $\pm S . D(n=3)$ of three replicates where each replicate constituted three plants/pot. Mean values followed by different letters are significantly different at $p \leq 0.05$ according to DMRT test. 

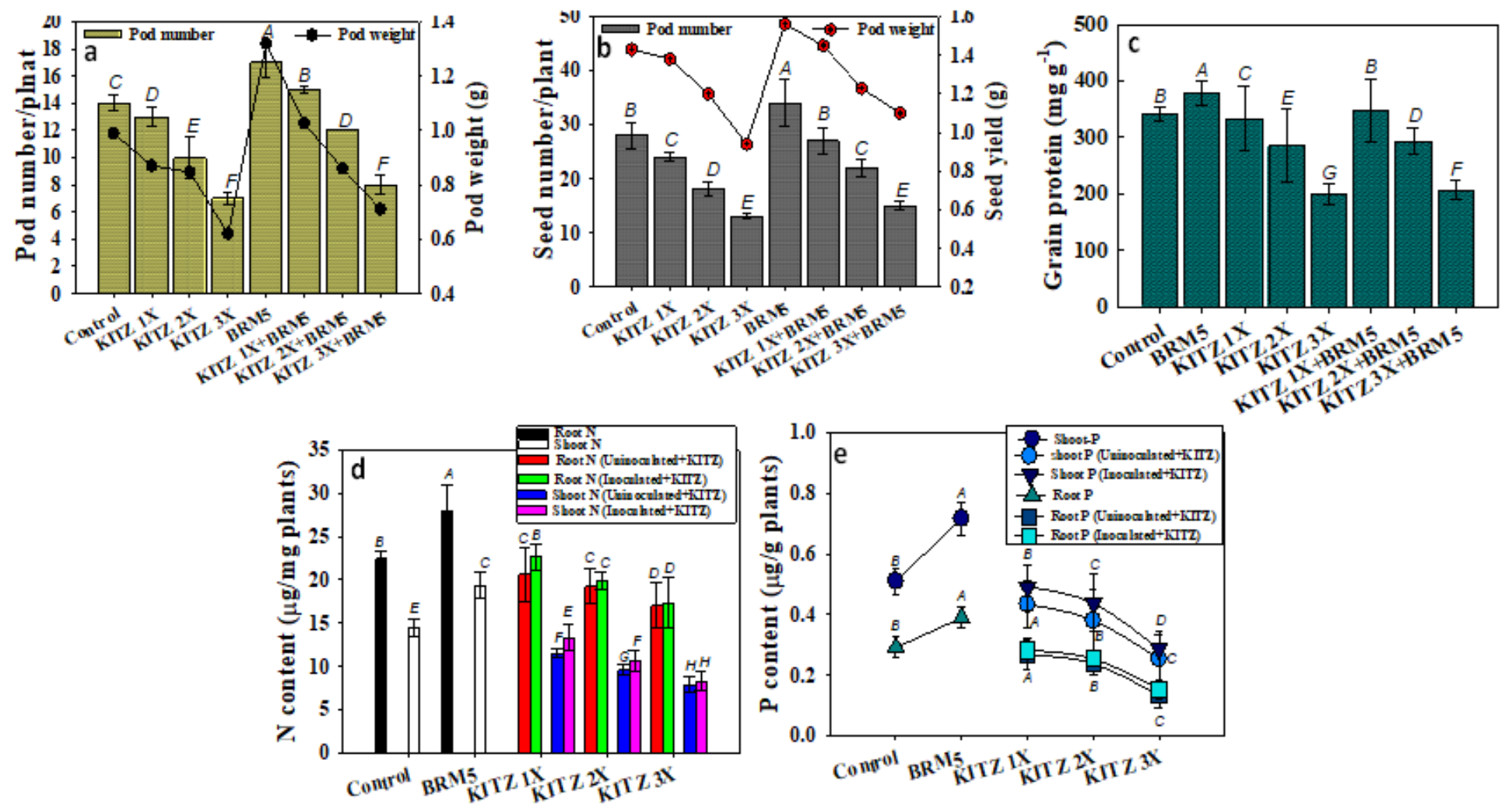

Figure 6

Bio-inoculation impact of M. ciceri BRM5 on C. arietinum plants on: pod number and yield (panel a), seed number of seed yield (panel b), grain protein (panel c), $\mathrm{N}$ content (panel d) and $\mathrm{P}$ content (panel e) grown in sandy clay loam soil treated with 96,192 and $288 \mu \mathrm{gKTZkg}-1$ soil. The bar and line diagrams represent the mean \pm S.D $(n=3)$ of three replicates where each replicate constituted three plants/pot. Mean values followed by different letters are significantly different at $p \leq 0.05$ according to DMRT test. 

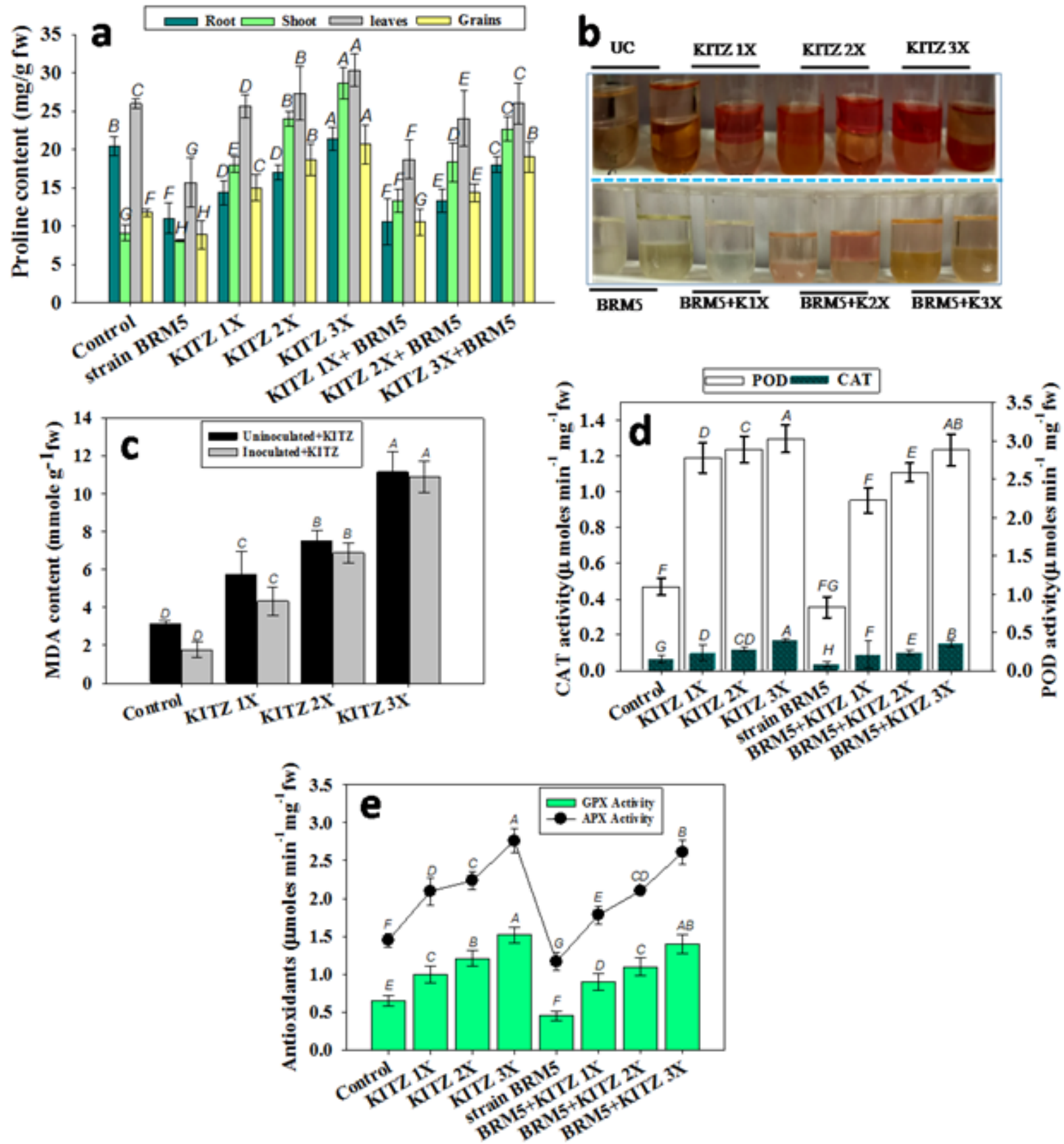

Figure 7

Bio-inoculation impact of M. ciceri BRM5 on proline content (panel a) antioxidant enzymes: GPX (panel b), APX (panel c) CAT (panel d) and MDA content (panel e) of $C$. arietinum plants grown in sandy clay loam soil treated with 96 (1X), $192(2 X)$ and $288(3 X) \mu g K T Z k g-1$ soil. The bar and line diagrams represent the mean $\pm S . D(n=3)$ of three replicates where each replicate constituted three plants/pot. Mean values followed by different letters are significantly different at $p \leq 0.05$ according to DMRT test. 


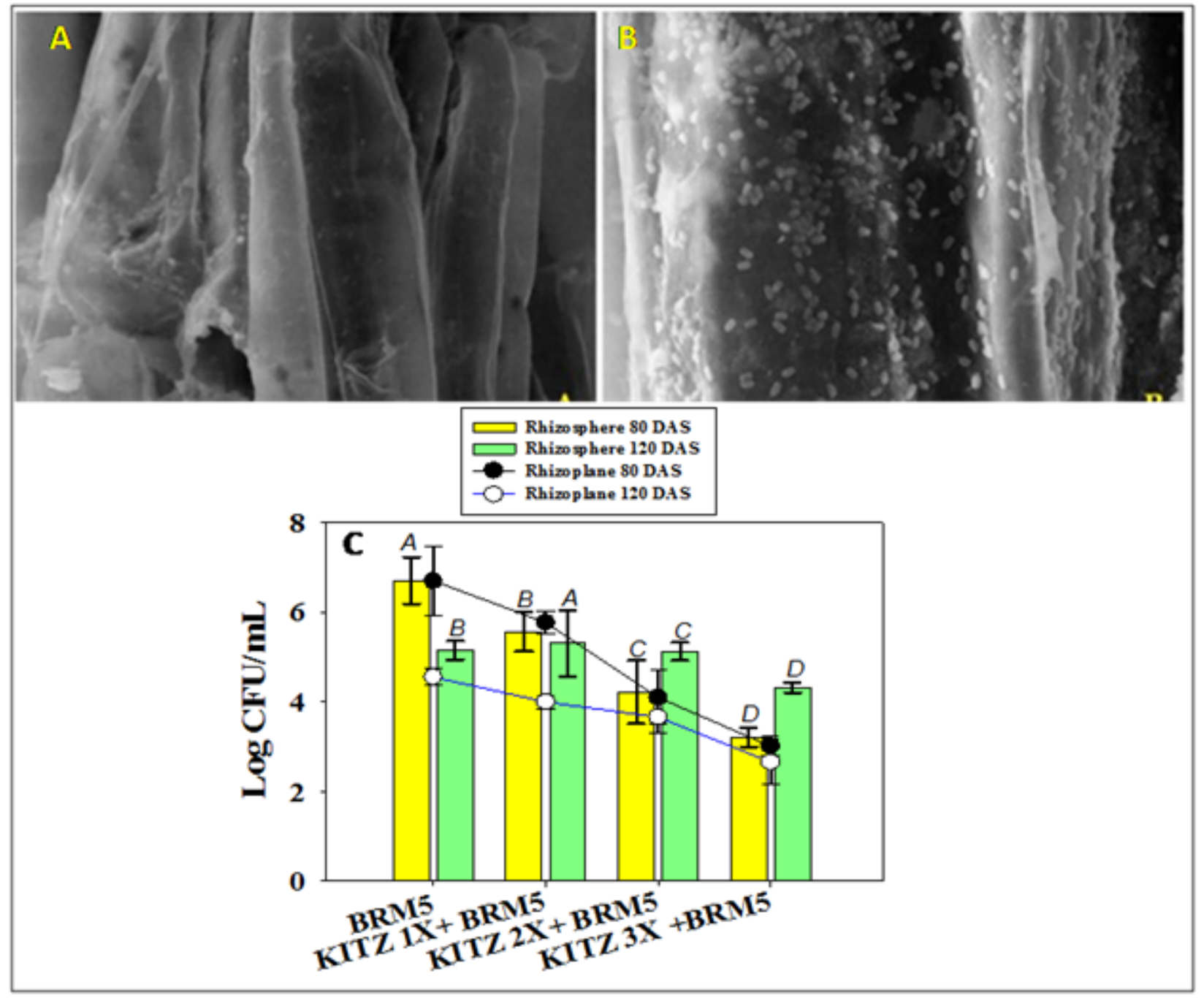

Figure 8

Colonization of M. ciceri strain BRM5 on root surface of $\mathrm{C}$. arietinum plants using scanning electron microscopy; uninoculated control showing no colonization on roots (panel A) inoculated and treated with kitazin showing adherence of bacteria on root surface (panel B). Rhizoplane and rhizosphere colonization in the presence of different concentrations of kitazin at two different seeding stages (80 and 120 DAS) (panel C).

\section{Supplementary Files}

This is a list of supplementary files associated with this preprint. Click to download.

- supplimenatry.docx 